\title{
论文
}

\section{4年新疆于田 $M_{\mathrm{s}} 7.3$ 地震地表破裂带精细填图 及其破裂特征}

袁兆德 ${ }^{1}$, 刘静 $^{2^{*}}$, 李雪 ${ }^{3}$, 徐晶 ${ }^{1}$, 姚文倩 ${ }^{1}$, 韩龙飞 ${ }^{2}$, 李涛 ${ }^{1}$

1. 中国地震局地质研究所地震动力学国家重点实验室, 北京 100029 ;

2. 天津大学地球系统科学学院, 天津 300072 ;

3. 中国地震局地震研究所, 中国地震局地震大地测量重点实验室, 武汉 430071

* 通讯作者, E-mail: liu_zeng@tju.edu.cn

收稿日期: 2020-04-14; 收修改稿日期：2020-08-13; 接受日期：2020-08-27; 网络版发表日期: 2020-11-16

国家自然科学基金项目(批准号: 41902216、U1839203)和中央级公益性科研院所基本科研业务项目(编号: IGCEA1814、IGCEA1812)资助

摘要大比例尺地震地表破裂带精细填图是研究强震破裂特征及机理的关键数据, 为理解破裂动态过程提供重 要的观测约束. 青藏高原中西部的强震地表破裂研究因发震地点偏远不易到达而成为薄弱环节. 文章利用无人机 航拍新技术，详细解译获得了2014年于田 $M_{\mathrm{s}} 7.3$ 地震地表破裂展布图. 此次地震在阿尔金断裂西段南硝尔库勒断 裂(南段 S1)、硝尔库勒断裂(中段 S2) 以及阿什库勒断裂(北段S3)上分别产生了16、6.9和14.2km的地表破裂. 南段 平均左旋位错为 $(52 \pm 25) \mathrm{cm}$, 最大为 $\sim 90 \mathrm{~cm}$; 北段平均左旋位错为 $(36 \pm 21) \mathrm{cm}$, 最大为 $\sim 84 \mathrm{~cm}$. 共统计了 5308 处裂缝 宽度，南段平均宽度为 $(85 \pm 71) \mathrm{cm}$, 最宽可达 $700 \mathrm{~cm}$; 中段平均宽度为 $(39 \pm 21) \mathrm{cm}$, 最宽可达 $243 \mathrm{~cm}$; 北段平均宽度 为 $(61 \pm 44) \mathrm{cm}$, 最宽可达 $340 \mathrm{~cm}$. 另外, 南段平均拉张量为 $(3.4 \pm 2.9) \mathrm{m}$, 最大可达 $17 \mathrm{~m}$; 中段平均拉张量为 (4.3 \pm 3.6$)$ $\mathrm{m}$, 最大为 $13 \mathrm{~m}$; 北段平均拉张量为 $(1.7 \pm 1.6) \mathrm{m}$, 最大为 $6 \mathrm{~m}$. 平均裂缝宽度和拉张量在弯曲和阶区部位均显示衰 减的趋势。千田地震和其他全球走滑型地震的地表破裂在弯曲、阶区、断裂分叉等断裂几何复杂部位的宽度大 于平直段，表明断裂几何结构对破裂宽度具有明显的控制作用. 硝尔库勒与南硝尔库勒断裂锐角相交区域发育的 大量裂缝可能指示构造拉张部位对近断裂分布式变形的控制, 为地震动态破裂的数值模拟提供了观测约束. 于田 地震还造成军见的大量伴生地震震动地表破坏，在地震震动的影响下含水盐层可能触发了缓坡度洪积扇的失稳， 形成了密集的滑坡和地暂系。这些分布式变形以及浅表伴生变形是地震破裂扩展过程与断裂几何结构耦合关系 的直接响应, 并暗示破裂在穿过阶区后可能在阿什库勒断裂上双向扩展.

关键词阿尔金断裂, 于田地震, 地震地表破裂带, 滑坡, 同震位移, 破裂带宽度

\section{1 引言}

揭示地震破裂在深部和地表的位移分布以及断层
三维几何结构是解剖地震的重要方面之一, 对理解地 震孕育过程、破裂扩展以及地震灾害分布规律具有重 要意义(Sieh等, 1993; Oskin等, 2012; Klinger等, 2018).

$\begin{array}{ll}\text { 中文引用格式: } & \text { 袁兆德, 刘静, 李雪, 徐晶, 姚文倩, 韩龙飞, 李涛. 2021. 2014年新疆于田 } M_{\mathrm{s}} 7.3 \text { 地震地表破裂带精细填图及其破裂特征. 中国科学: 地球科学, 51 } \\ & \text { (2): 276-298, doi: 10.1360/SSTe-2020-0100 } \\ \text { 英文引用格式: } & \text { Yuan Z, Liu-Zeng J, Li X, Xu J, Yao W, Han L, Li T. 2021. Detailed mapping of the surface rupture of the 12 February 2014 Yutian } M_{\mathrm{s}} 7.3 \text { earthquake, } \\ & \text { Altyn Tagh fault, Xinjiang, China. Science China Earth Sciences, 64(1): 127-147, https://doi.org/10.1007/s11430-020-9673-6 }\end{array}$ 
其中，地震地表破裂的空间展布和位移分布是研究断 裂地震破裂行为的关键(Wells和Coppersmith，1994; Wesnousky, 2006). 前人在收集整理全球范围内地震地 表破裂带基本参数的基础上，建立了不同类型断层的 位移风险性概率分析关系式，试图揭示断层在发生地 震时主破裂和分布式破裂位移分布概率，为重大工程 和生命线工程设计提供建议(Youngs等，2003; Petersen 等, 2011; Moss和Ross, 2011). 但是, 较少的震例样本降 低了分析的准确性，如建立的走滑断层位移风险性概 率分析关系式仅基于 8 个地震实例(Petersen等，2011). 另外，地震地表破裂带分布式破裂与主破裂具有不同 的变形分布特征, 其分布较为复杂, 位移大小与主断层 的关系不确定性较大，而后者具有变形局部化的特征 (徐锡伟等，2008)，并且位移大小与主断层的关系更为 清楚(Petersen等, 2011). 近年来, 随着合成孔径雷达干涉 测量(InSAR)、激光雷达(LiDAR)、光学影像对比、无 人机航拍以及亚米级卫星影像的应用, 获得了越来越 多的精细地震地表破裂带展布图以及位移分布(Massonnet等, 1993; Klinger等, 2005; Oskin等, 2012; Choi等, 2018; Scott等, 2019), 提高了对地震破裂规律的认识.

2014年2月12日在新疆于田西昆仑山硝尔库勒盆 地发生了 $M_{\mathrm{s}} 7.3$ (美国USGS， $M_{\mathrm{w}} 6.9$ )强烈地震，震源机 制解显示为带有正断分量的走滑型地震(李金和王琼, 2015). 该强震主发震断层为阿尔金断裂带西段的阿什 库勒断裂和南硝尔库勒断裂(Tapponnier等，2001). 震 后多位学者对地震地表破裂进行了野外调查和卫星影 像解译，基本上确定了地震地表破裂展布范围及其特 征, 但是缺少对地震地表破裂展布情况的精细刻画( $\mathrm{Li}$ 等, 2016; 徐岳仁等, 2015). 此次地震产生的地表破裂 最大左旋位移仅为 $1 \mathrm{~m}$, 而且大部分地段位移只有几 十厘米( $\mathrm{Li}$ 等, 2016), 所以现有的卫星影像分辨率并不 能满足对地表破裂精细填图. 此外, 地震处于高海拔无 人区(海拔 $4500 \mathrm{~m}$ 以上), 长时间的野外精细填图具有极 大的挑战性. 为了获得更精细的地震地表破裂展布图, 我们利用近几年广泛应用的无人机航拍技术对于田地 震地表破裂进行了航拍，基于生成的高分辨率正射镶 嵌图完成了对地表破裂的详细解译.

\section{2 区域地震构造背景}

阿尔金断裂带是亚洲大陆内部最引人注目的巨型
活动断裂之一, 分割了塔里木盆地和柴达木盆地, 是青 藏高原西北部的天然边界(图1a). 该断裂主体部分长 达 $1600 \mathrm{~km}$ ，是协调和吸收印度板块向欧亚板块俯冲 推挤所造成巨大应变的重要断裂之一(Molnar和Tapponnier, 1975; Tapponnier等, 2001; Avouac和Tapponnier, 1993), 其活动起始时间可能始于晚渐新世-早中 新世(Yue等，2001)，左旋位错可达350 470km(Yin等, 2002; Cowgill等, 2003; Ritts和Biffi, 2000). 在 $83.18^{\circ} \mathrm{E}$ 处, 阿尔金断裂向西分成两支, 与喀喇昆仑断裂共同组 成了西昆仑块体的边界(邓起东等, 2002). 北支为康西 瓦断裂(又称喀拉喀什断裂), 呈近EW和NW-SE延伸, 长约 $650 \mathrm{~km}$. 该断裂主要表现为单支断裂, 以左旋运动 为主, 晚第四纪和现今 GPS的走滑速率为 $2.6 \sim 8 \mathrm{~mm} \mathrm{a}^{-1}$ (Shen等, 2001; Wright等, 2004; Loveless和Meade, 2011；Li等, 2012; Gong等, 2017; Peltzer等, 2020), 而 弹性块体模型结合GPS观测数据计算获得的走滑速率 为 $2 \mathrm{~mm} \mathrm{a}^{-1}$ (Meade, 2007). 南支为龙木错-郭扎错断裂 系，主要由龙木错断裂、郭扎错断裂、南硝尔库勒断 裂、阿什库勒断裂、玉龙喀什河断裂等组成(图1), 呈 左阶斜列展布，总体走向SW-NE. 其中龙木错断裂、 郭扎错断裂和阿什库勒断裂晚第四纪左旋滑动速率均 小于 $3 \mathrm{~mm} \mathrm{a}^{-1}$ (Chevalier等, 2017; Pan等, 2015), 但弹性 块体模型结合GPS观测数据计算获得的龙木错-郭扎 错断裂系走滑速率高达13 18mm a ${ }^{-1}$ (Meade, 2007).

阿尔金断裂在地表迹线清晰，晚第四纪断错地貌 广泛发育，且保存了总长 $1100 \mathrm{~km}$ 的地震地表破裂带 遗迹(国家地震局阿尔金活动断裂带课题组, 1992), 表 明其具有较强的强震发震能力. 其中康西瓦断裂沿着 喀拉喀什河谷发育了 $55 \sim 80 \mathrm{~km}$ 的地震地表破裂带, 平 均同震位错 $6 \mathrm{~m}$, 震级可达 $M_{\mathrm{w}} 7.3 \sim 7$.6 (付碧宏等, 2006; Li等, 2012). 在两百多年的历史地震记录中, 该断裂仅 记录到未产生明确地震地表破裂的1924年民丰 M7.2 双震(顾功叙, 1983). 而该断裂西段南支玉龙喀什断裂 在2008年发生了 $M_{\mathrm{w}}$ 7.1强震(图1b), 产生了 $31 \mathrm{~km}$ 的地震 地表破裂带(Xu等, 2013). 与青藏高原内部和周缘的大 型走滑断裂相比, 如鲜水河-小江断裂、东昆仑断裂和 海原断裂等(Allen等，1991; 陈杰等，2003; 闻学泽等, 2008; 国家地震局地质研究所和宁夏回族自治区地震 局，1990)，阿尔金断裂缺少百公里破裂尺度的历史强 震事件记录. 但是古地震数据以及地震地表破裂带分 布均显示该断裂曾发生过 $M_{\mathrm{w}} 8.1$ 地震, 破裂长度可达 

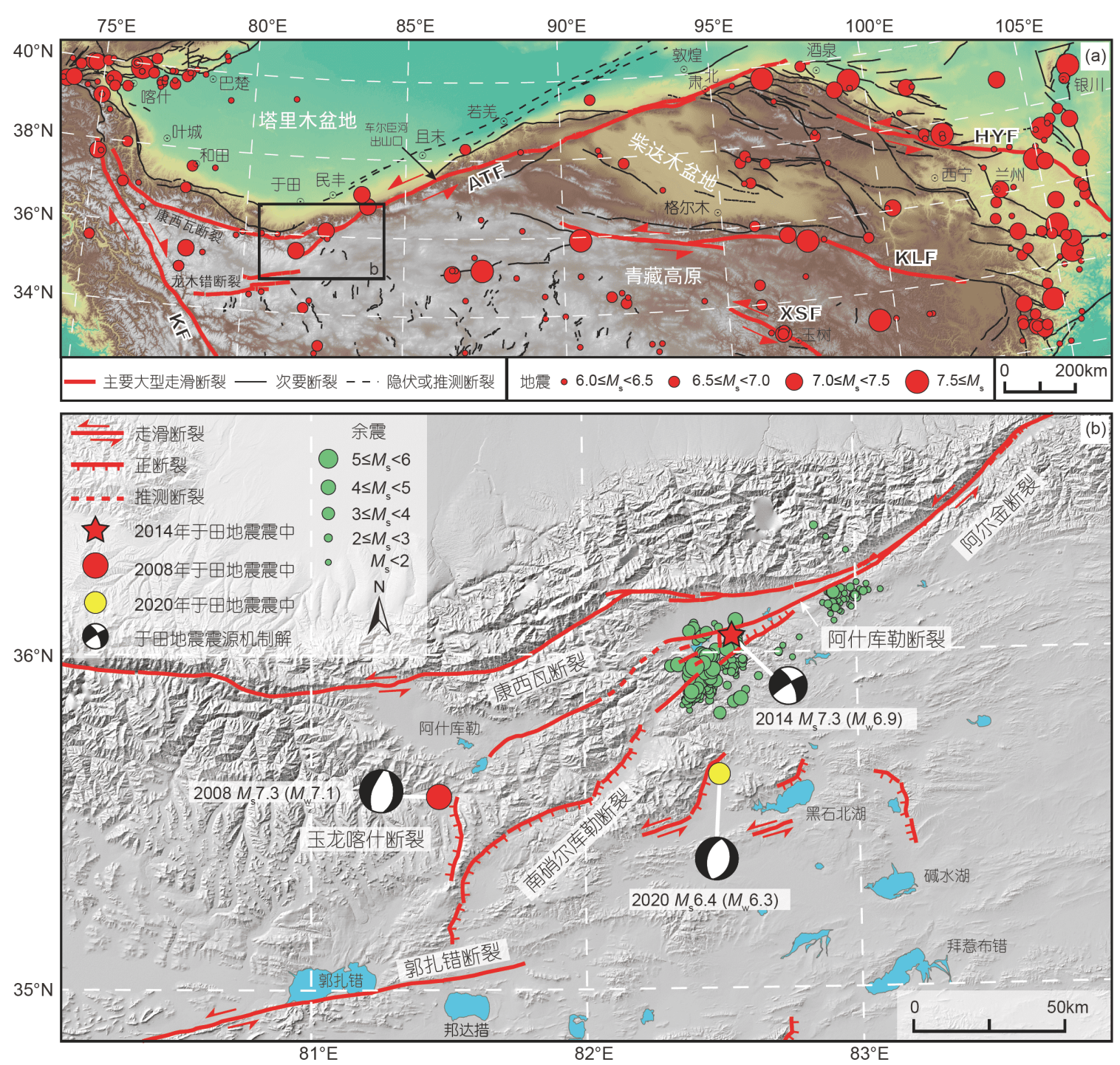

图 1 2014年于田地震区域活动构造背景图

(a) 青藏高原北部地震构造图(据袁兆德等, 2019 修改), 显示阿尔金断裂在 $85^{\circ} \mathrm{E}$ 以东缺少强震历史地震记录. (b) 2014年于田地震周围活动断裂 展布及主余震位置图; ATF, 阿尔金断裂; HYF, 海原断裂; KLF, 东昆仑断裂; XSF, 鲜水河断裂; KF, 喀喇昆仑断裂; 断裂据Tapponnier等(2001)修 改; 余震来自房立华等(2015)

300km以上(Washburn等, 2003; Elliott等, 2015; Yuan等, 2018; Shao等, 2018).

\section{3 研究方法}

无人机航拍在近几年开始大量应用在野外活动构 造调查中，是快速获取高分辨率地貌的有效手段之一 (Bemis等，2014; Bi等，2017; Gao等，2017). 我们于 2019年7月18 26日利用大疆精灵PHANTOM 4 PRO
V2.0无人机对2014年于田地震地表破裂带进行了航拍 (图2a). 依靠无人机内置GPS定位系统，对地表破裂实 行分块航拍, 其中每块航拍区域长度小于 $2 \mathrm{~km}$, 宽度小 于 $1 \mathrm{~km}$. 根据航拍区域地形，航高设置为 $100 \sim 350 \mathrm{~m}$ 不 等，航向重叠率为 $80 \%$ ，旁向重叠率为 $70 \%$. 在室内利 用Agisoft Metashape Professional软件分别对每块航拍 区域的照片进行单独处理，生成高分辨率正射镶嵌图 (分辨率 $3.5 \sim 10.3 \mathrm{~cm}$ ) 和数字高程模型 (分辨率 14 77cm), 然后在ArcGIS软件中基于正射镶嵌图对地 


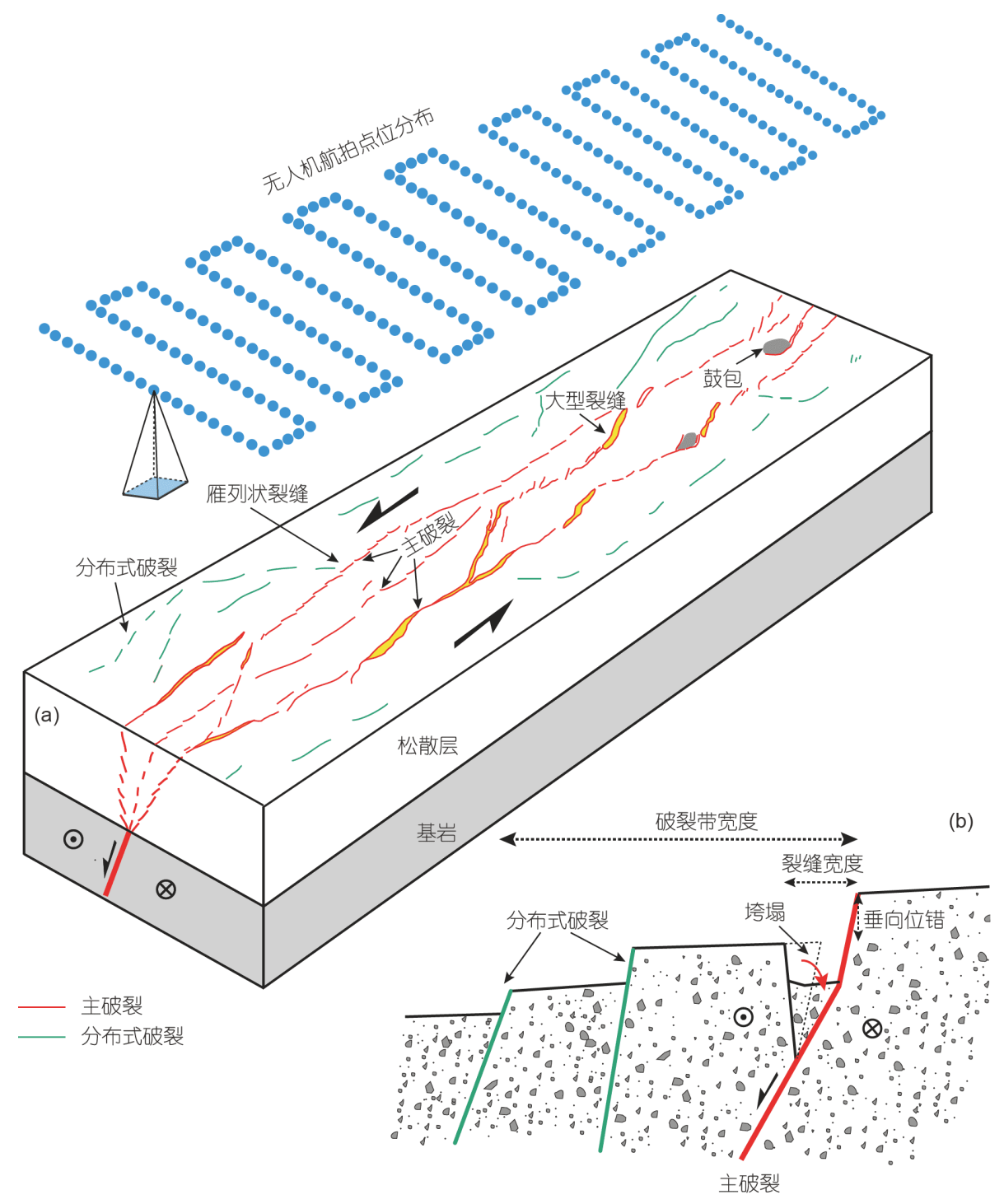

图 2 针对地震地表破裂的无人机航拍技术图

(a) 上图为无人机航拍路径及拍照点位分布, 蓝色圆点代表相机拍照点位; 下图为地表破裂样式, 包括雁列状裂缝、鼓包等. 变形带在近地表 变宽, 产生了除主破裂之外的分布式破裂. (b) 主破裂与分布式破裂剖面图, 破裂带宽度为分布式破裂和主破裂的分布宽度. 裂缝宽度为裂缝 两壁的水平拉张宽度. 红色线段表示主破裂, 绿色线段表示分布式破裂

表破裂带进行详细解译. 由于在整个航拍区域没有布 置控制点, 所以相邻航拍区块的镶嵌图重叠区存在 $<6 \mathrm{~m}$ 的偏差.

\section{4 地震地表破裂特征}

深部断层向地表错动过程中, 由于近地表围压的 降低而发生分散，形成了除主破裂之外的分布式破裂 (图2). 主破裂展布较为集中, 更加连续, 且具有较为固
定的走向, 在深部与主断层相连. 分布式破裂较为分 散, 不连续, 走向不确定性大, 在深部不一定与主断层 直接相连. 在本文中, 将与破裂带整体延伸方向一致且 较为集中分布的破裂划分为主破裂，而将远离主破裂 带的次级破裂划分为分布式破裂. 除了上述构造成因 的地表破裂外, 地震震动效应也会产生滑坡、崩塌以 及砂土液化等非构造成因的伴生地表变形. 为了更加 清晰地展示于田地震地表破裂分布特征, 本文对上述 地表破裂和伴生地表变形进行了区分(图3). 

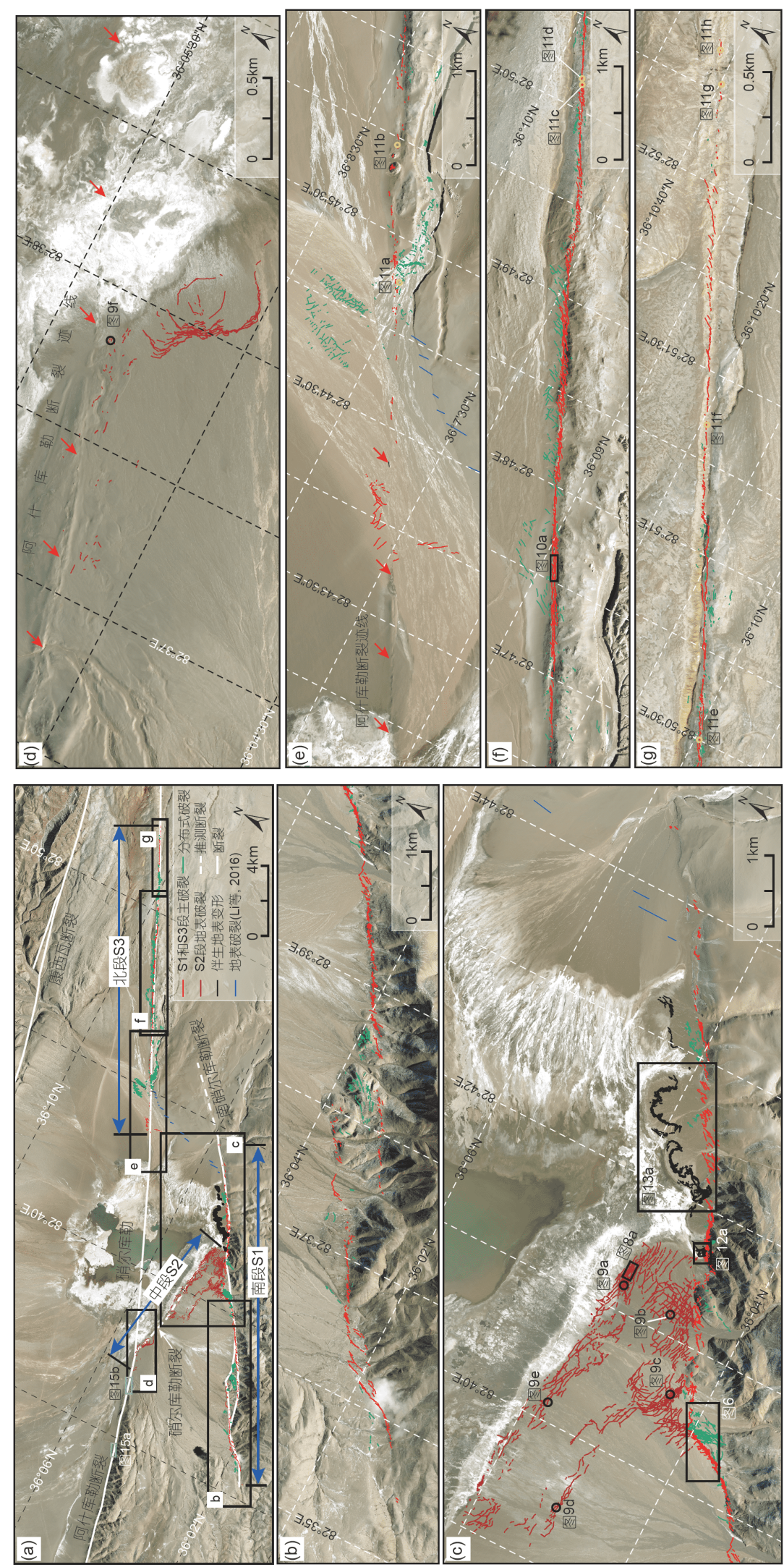

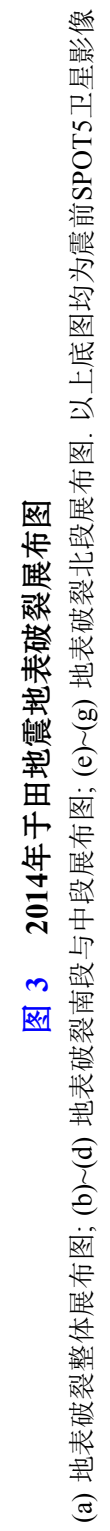


通过解译高分辨率正射影像获得的地震地表破裂 展布图显示: 2014年于田 $M_{\mathrm{s}} 7.3$ 地震在阿尔金断裂西段 南支断裂阿什库勒断裂和南硝尔库勒断裂上产生了同 震地表破裂, 并且在两条断裂之间形成了总体呈近 $\mathrm{EW}$ 走向的地表破裂(图3). 根据空间几何展布，地震地表 破裂可分为三段(图3a): 南段 $\mathrm{S} 1$ 、中段 $\mathrm{S} 2$ 以及北段 $\mathrm{S} 3$. 南段位于硝尔库勒盆地南缘，呈 $\mathrm{NE} 60^{\circ}$ 展布，全长 $16 \mathrm{~km}$; 中段 $\mathrm{S} 2$ 整体与南段 $\mathrm{S} 1$ 相交 $43^{\circ}$ ，呈 $\sim \mathrm{NW} 77^{\circ}$ 展 布，破裂带宽度东宽西窄，全长 $6.9 \mathrm{~km}$; 北段 $\mathrm{S} 3$ 位于硝 尔库勒湖北东侧, 呈 $\sim \mathrm{NE} 65^{\circ}$ 展布, 全长 $14.2 \mathrm{~km}$. 此外, 风积作用在北段与南段之间的阶区内比较强，过去五 年内在局部区段风沙堆积厚度大于地震破裂垂向分量 从而埋藏了部分地表破裂，致使我们在野外调查和无 人机航拍影像中均未发现地表破裂遗迹，所以阶区内 的地表破裂迹线采用了 $\mathrm{Li}$ 等(2016)的数据.

2014年于田地震地表破裂整体上呈左旋兼正断, 所以破裂以张剪切裂缝为主，局部亦可见少量的左旋 位错以及逆冲陡坎. 垂向位错多在 $40 \mathrm{~cm}$ 以内 $(\mathrm{Li}$ 等, 2016), 以分辨率为 $14 \sim 77 \mathrm{~cm}$ 的数字高程模型很难测量 绝大部分垂向位错. 为了充分挖掘位错信息, 我们基 于正射镶嵌图(分辨率< 10cm) 测量了 5308 个裂缝宽 度，获得了此次地震地表裂缝宽度分布图(图4和图5), 其中测量误差主要来源于影像分辨率. 裂缝宽度为垂 直于裂缝走向的两壁水平拉张量，会受断层产状、地 形坡度、重力作用等因素影响(图2b)，在裂缝两壁无 垮塌的情况下, 裂缝宽度相当于正断层在倾向上的水 平拉张量. 除了单条裂缝宽度之外, 我们还计算了跨 破裂带所有裂缝宽度之和，相当于获得了破裂带拉张 量(图4e和图 $5 \mathrm{c}$ ). 假定地表破裂的拉张量与走滑位移 或垂向位移的比值固定，那么拉张量的变化可以反映 走滑位移或垂向位移沿破裂带走向的变化. 已有震例 表明正断层的拉张量与垂向位错的变化趋势是同步的 (Ferrario和Livio, 2018), 所以裂缝宽度的变化可能反映 了垂向位错变化.

\section{1 南段S1}

南段 $\mathrm{S} 1$ 位于硝尔库勒盆地南侧山麓地带, 由不连 续的斜列张性破裂、张剪切走滑破裂、剪切走滑破裂 和挤压破裂等破裂单元组合而成. 该段最为复杂的破 裂组合位于 $8 \sim 10 \mathrm{~km}$ 处，由6对左旋剪切挤压破裂和张 性破裂以及主破裂南侧一系列平行的张裂缝组成(图
6), 其中主破裂上的张裂缝宽度可达 $4 \mathrm{~m}$ ，挤压鼓包高 度可达 $0.7 \mathrm{~m}$ (图7). 南段 $\mathrm{S} 1$ 大部分破裂主要表现为张 性和张剪切裂缝, 其中裂缝平均宽度为 $(85 \pm 71) \mathrm{cm}$, 最 大宽度可达6 7m. 破裂带平均拉张量为 $(3.4 \pm 2.9) \mathrm{m}$, 最 大可达 $17 \mathrm{~m}$. 该段几何结构较为复杂，在 $1.5 、 7.5$ 和 $8.5 \mathrm{~km}$ 处发育了由破裂带走向发生变化而形成的三个 弯曲, 以及在 $4.5 \mathrm{~km}$ 处发育了一处阶区(图 $4 \mathrm{a})$. 以每 $400 \mathrm{~m}$ 计算的平均裂缝宽度和跨破裂带的拉张量在弯 曲和阶区位置均有减小的趋势(图4d和图4e). 另外, 拉 张量在伴生浅地表变形密集区达到峰值(图4e).

在该段测量了 6 处左旋位错，加上前人的 18 处 $(\mathrm{Li}$ 等，2016)，共获得了 24 个左旋位移数据，平均左旋位 错为 $(52 \pm 25) \mathrm{cm}$. 在最大走滑位错点, 前人利用LiDAR 数据获得的左旋位错为 $(1 \pm 0.05) \mathrm{m}(\mathrm{Li}$ 等, 2016), 而基于 高分辨率正射航拍影像量取的左旋位错为 $90 \mathrm{~cm}$ (见 图6a). 此外, 该段最大正断垂向位移为 $0.3 \sim 0.75 \mathrm{~m}$ ( $\mathrm{Li}$ 等, 2016).

\section{2 中段 $\mathrm{S} 2$}

中段S2分布在晚第四纪冲洪积扇上，总体延伸方 向与硝尔库勒湖岸线平行, 主要由走向为 $\mathrm{NWW}$ 和 NNE的两组张裂缝组成(图3c), 其裂㖓平均宽度为(39 $\pm 21) \mathrm{cm}$, 最宽可达 $243 \mathrm{~cm}$. 破裂带平均拉张量为 $(4.3$ $\pm 3.6) \mathrm{m}$, 在中段 $\mathrm{S} 2$ 与南段 $\mathrm{S} 1$ 交汇区达到最大值 $13 \mathrm{~m}$ (图5c). 在与南段 $\mathrm{S} 1$ 相交处, 地表破裂主要为两组不同 走向的张裂缝形成的网格状破裂(图3c), 分布范围最 宽可达 $1.8 \mathrm{~km}$. 在 $82^{\circ} 41^{\prime} \mathrm{E} \sim 82^{\circ} 39^{\prime} \mathrm{E}$ ，地表破裂分为两 条近平行的间隔为 $400 \sim 450 \mathrm{~m}$ 的破裂带. 在 $82^{\circ} 39^{\prime} \mathrm{E}$ 以 西，存在 $1 \mathrm{~km}$ 的地表破裂空段，未见任何地表破裂; 继续往西, 破裂带明显变窄, 仅150 300m, 且在尾端 破裂走向转变为 $\mathrm{NE}$, 与阿什库勒断裂平行(图3d). 地表 破裂空区以西(S2-1)的裂缝宽度变化较大(图5a), 在 $1.5 \mathrm{~km}$ 处最大可达 $2 \mathrm{~m}$, 然后向东西两侧迅速衰减至 $\sim 60$ 和 $20 \mathrm{~cm}$. 如果每 $200 \mathrm{~m}$ 计算裂缝平均宽度, 那么中 段S2-1裂缝均值分布在20 80cm(图5b). 地表破裂空区 以东 $(\mathrm{S} 2-2)$ 的裂缝宽度最大为 $2 \mathrm{~m}$, 但总体变化弱于 S2-1, 裂缝均值分布在20 60 cm内(图5b).

在中段 $\mathrm{S} 2$, 仅发现两条长度分别为 70 和 $150 \mathrm{~m}$ 的先 存断层陡坎, 其走向为 $\mathrm{SE} \sim 45^{\circ}$, 垂向位错为 45 和 $56 \mathrm{~cm}$, 且与地震新产生的张裂缝相交(图8). 中段冲洪积扇上 发育的大量小型冲沟是判断破裂运动性质的良好线性 

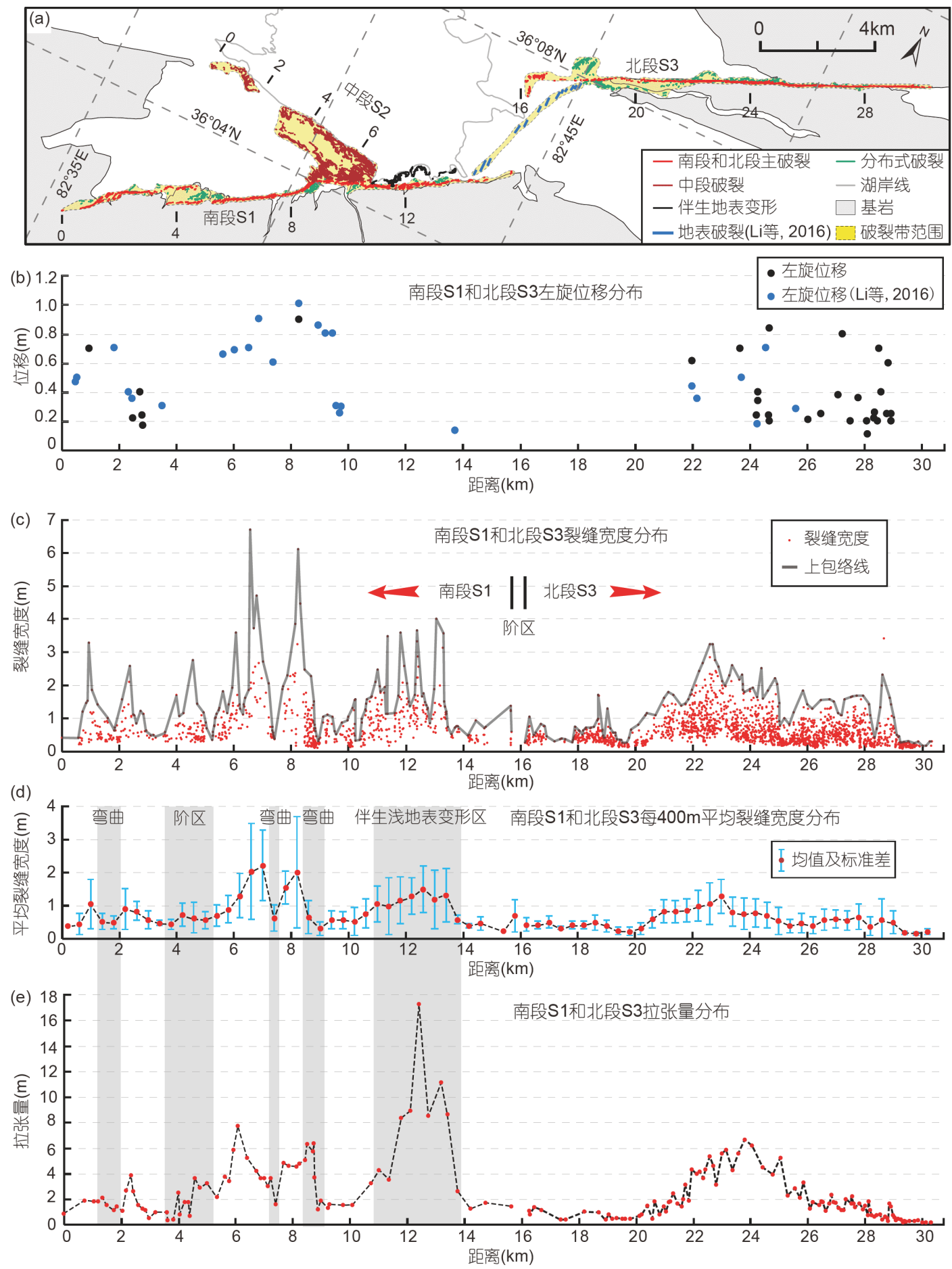

图 4 2014年于田地震南段和北段地表破裂沿断裂走向的变化

(a) 地震地表破裂带宽度及展布图, 显示破裂带在阶区、弯曲和断裂分叉等几何复杂部位较宽, 而且在松散沉积物覆盖区比基岩区分布宽. 此 外, 蓝色线段表示南段 $\mathrm{S} 1$ 与北段 S3之间的阶区破裂迹线, 来自 $\mathrm{Li}$ 等(2016). (b) 南段 S1和北段 S3 走滑位错分布. (c) 南段 S1和北段 S3裂缝宽度分 布, 最大宽度可达 $6.7 \mathrm{~m}$. (d) 基于图(c)数据, 沿破裂带 $\mathrm{S} 1$ 和 $\mathrm{S} 3$ 整体走向每 $400 \mathrm{~m}$ 计算的裂缝平均宽度分布, 显示裂缝宽度在弯曲和阶区附近有减 小的趋势, 灰色区域表示弯曲、阶区和伴生浅地表变形区的范围. (e) 南段S1和北段S3拉张量分布, 显示在弯曲和阶区附近有减小的趋势, 而 在伴生浅地表变形区增大 

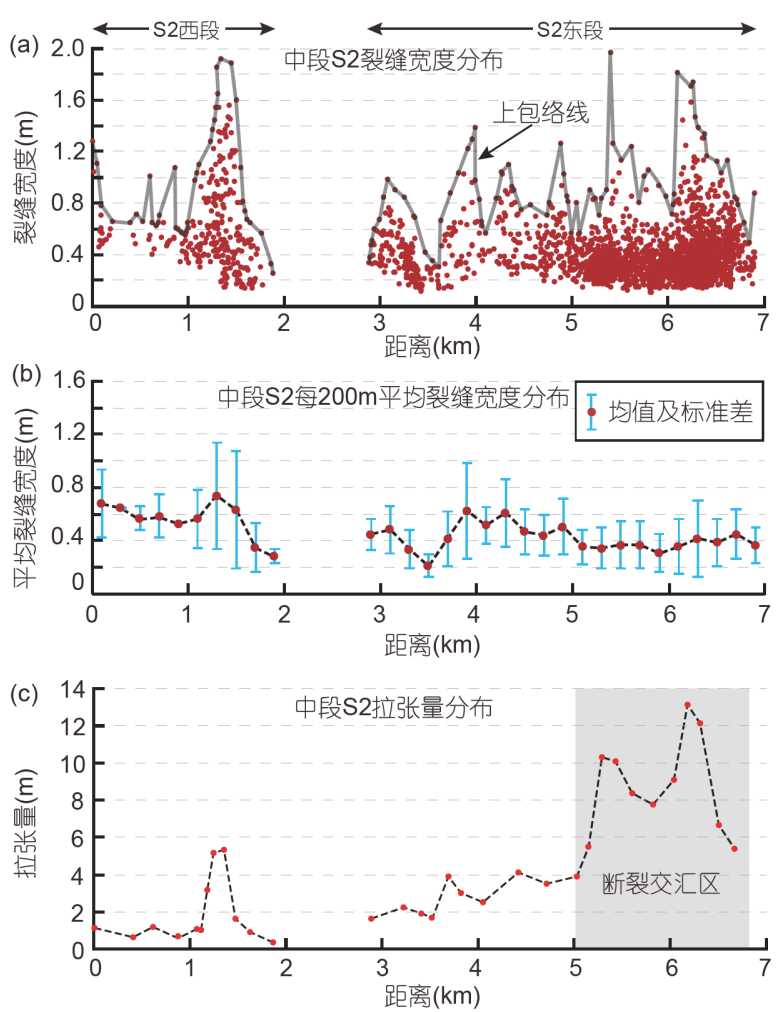

图 52014 年于田地震中段地表破裂沿断裂走向的变化

(a) 中段 $\mathrm{S} 2$ 裂缝宽度分布, 最大宽度 $2 \mathrm{~m}$, 其中西段宽度变化较大, 呈 现向两侧减小的趋势, 东段整体变化较小. (b) 基于图(a)数据, 沿破 裂带S2总体走向每 $200 \mathrm{~m}$ 计算的裂缝平均宽度分布，其变化趋势与 图b类似. (c) 中段 $\mathrm{S} 2$ 拉张量分布, 显示拉张量在断裂交汇区最大. 灰 色区域代表断裂交汇区范围

标志. 通过野外实地考察和室内解译高分辨率影像, 发 现大部分断错冲沟以拉张位错为主，未发现右旋位移 (图9)，但 $\mathrm{Li}$ 等(2016)在该段观察到了 20cm的右旋位 错, 表明该段部分裂缝存在一定量的右旋位移.

\section{3 北段S3}

北段S3西起硝尔库勒湖北东侧洪积扇 $\left(82^{\circ} 43^{\prime} 50^{\prime \prime} \mathrm{E}\right)$, 向东止于基岩区 $\left(82^{\circ} 52^{\prime} 52^{\prime \prime} \mathrm{E}\right)$. 该段主破裂相对于南段 $\mathrm{S} 1$ 比较平直, 主要由一系列的左旋张剪切裂缝组成, 亦 可见少部分挤压鼓包(图10), 个别位置可见张剪切裂 缝切穿老的挤压鼓包(图11e). 由于大部分地表破裂位 于基岩区, 所以地表左旋位错参考标志稀少, 主要为 小型冲沟、草堆等(图11d 11f). 共实测了 25 个走滑位 错, 再加上 6 个前人数据 $(\mathrm{Li}$ 等, 2016), 总数据量为 31 个. 这些数据平均左旋位错为 $(36 \pm 21) \mathrm{cm}$, 最小位错为 $\sim 11 \mathrm{~cm}$, 最大值为 $\sim 84 \mathrm{~cm}$. 北段裂缝平均宽度为 $(61 \pm 44)$ $\mathrm{cm}$ ，最大可达 $340 \mathrm{~cm}$ ，总体上呈现中间向两侧递减的 趋势(图4d), 两端小型裂缝接近充填至平(图 $11 \mathrm{a} 、$ $11 \mathrm{~b} 、 11 \mathrm{~g} 、 11 \mathrm{~h})$. 破裂带平均拉张量 $(1.7 \pm 1.6) \mathrm{m}$ ，最大 为 $6 \mathrm{~m}$, 也呈现向破裂带两端递减的趋势(图4e). 相对 于南段 $\mathrm{S} 1$, 此段的平均裂缝宽度和拉张量分布更为简 单, 尤其是拉张量分布几乎呈正态分布, 可能与北段 相对平直的几何结构有关.

\section{5 伴生浅地表变形}

除了断层错动至地表产生破裂之外, 地震震动效 应也会引起地表失稳, 产生地表裂缝、砂土液化以及 滑坡等. 于田地震还产生了震动引发的大量地表破坏, 如洪积扇失稳下滑产生的滑坡和地堑系. 在硝尔库勒 湖南岸野外调查中, 发现两处保存良好的地震滑坡(分 别为 $\mathrm{L} 1$ 和 $\mathrm{L} 2$ ) 以及与湖岸近平行分布的地堑系(图3c、 12和13).

滑坡体 $\mathrm{L} 1$ 位于硝尔库勒湖南岸洪积扇上(图 $3 \mathrm{c}$ 和 图12), 由松散洪积物组成. 该滑坡体长 116m, 宽 $\sim 100 \mathrm{~m}$, 面积为 $7618 \mathrm{~m}^{2}$, 坡度为 $7.9^{\circ}$, 滑移方向为 $\mathrm{NW} 65^{\circ}$. 在滑坡体南侧可见呈NEE走向的张剪切裂缝. 滑坡体整体显示后缘拉张、前缘挤压，具体表现为后 缘发育了大小不一的拉张裂缝, 从十几厘米至 $7 \mathrm{~m}$ 不 等, 总宽度达到了 13m. 滑坡体前缘逆冲和两侧挤压 剪切形成的陡坎可分为三种(图12b和12e): 低角度逆 冲陡坎，可以清晰看到上盘逆冲到下盘之上，垂向高 度可达 $1.7 \mathrm{~m}$; 长条形挤压剪切形成的鼓包, 垂向位错 可达 $0.8 \mathrm{~m}$, 位于前缘两侧; 逆冲褶皱陡坎, 垂向位错 可达 $0.8 \mathrm{~m}$. 同时, 在滑坡体前缘可以看到由于两侧滑 移量的不同而产生的撕裂构造(图12d 12f), 断错的车 辙显示滑移差可达 $2.7 \mathrm{~m}$ (图12d).

在滑坡体L1北东侧 $~ 500 \mathrm{~m}$ 处也发育了另外一个滑 坡体L2, 其依然由松散洪积物组成(图3c 和图13). 该滑 坡体总体规模比L1要大, 其长 $237 \mathrm{~m}$, 宽 $157 \mathrm{~m}$, 面积达 $27842 \mathrm{~m}^{2}$, 坡度 $5.7^{\circ}$, 滑移方向为NW55 $5^{\circ}$. 同样, 在滑坡 体南侧可见呈NEE走向的雁列式张剪切裂缝. 该滑坡 体与L1破裂样式相似，前缘发育了低角度逆冲陡坎、 逆冲禇皱以及挤压剪切鼓包，后缘发育了大量拉张裂 缝(图14a), 同样也存在调节滑移差异形成的撕裂构造. 滑坡体后缘拉张裂缝总宽度为 $15 \mathrm{~m}$, 与 $\mathrm{L} 1$ 相当, 其中 裂缝最宽可达 $5.5 \mathrm{~m}$. 不同之处, L2发育的低角度逆冲 

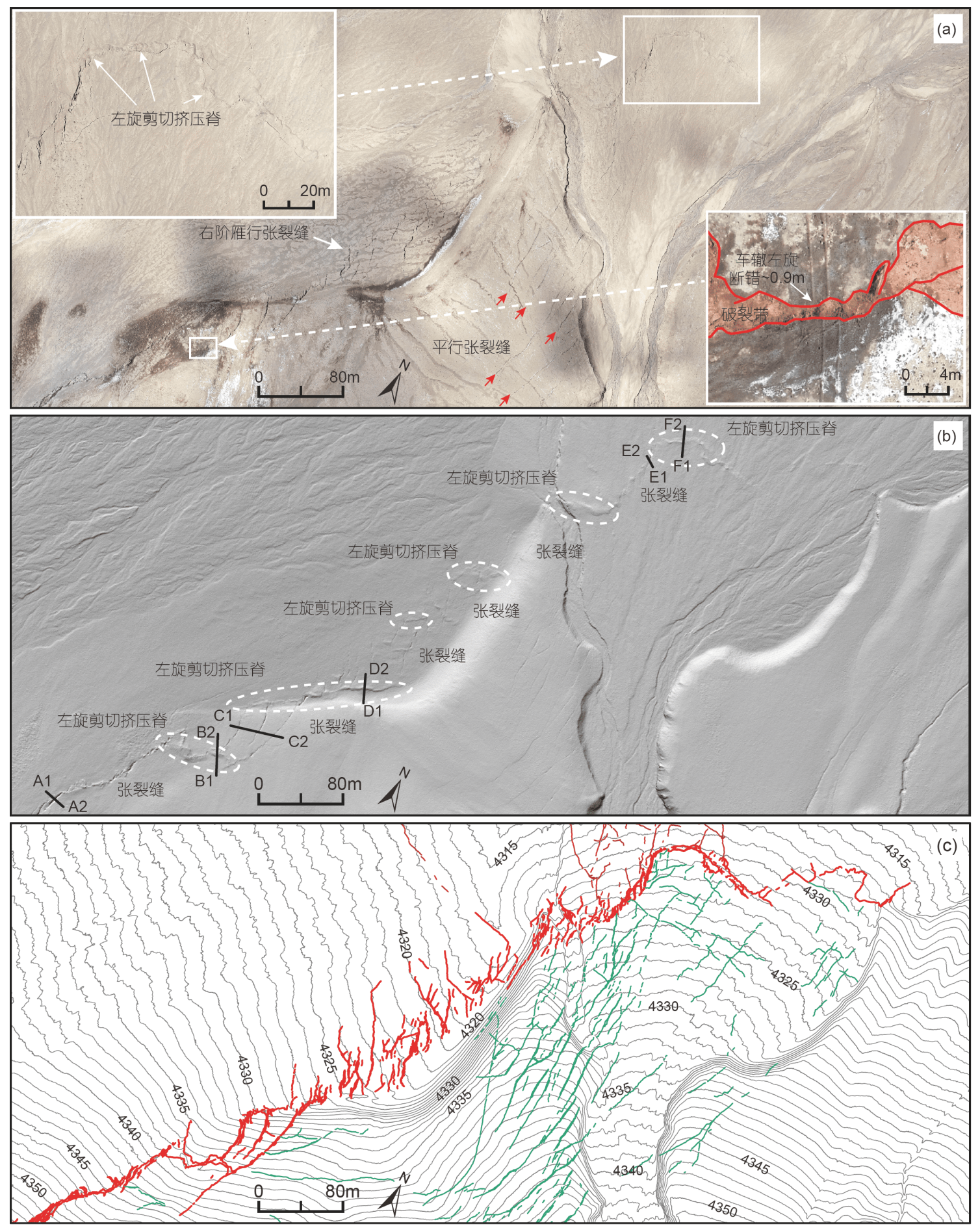

图 6 南段S1典型右阶雁行张剪切裂缝、左旋剪切挤压脊及平行裂缝

位置见图3(c). (a) 正射镶嵌图, 右下角为南段 $\mathrm{S} 1$ 最大左旋位错; (b) 山影图以及地形剖面位置; (c) 断裂解译图, 等高线数值单位为 $\mathrm{m}$, 间距为 $1 \mathrm{~m}$. 断裂图例同图4(a)

陡坎位于逆冲褶皱前方，并且大致平行(图14b). 其中 逆冲陡坎和逆冲褶皱陡坎的高度分别可达 1.6和 1m.
除了以上两处典型的滑坡体外，在洪积扇上也发 育了大量的弧形地堑系以及挤压构造(图13和 

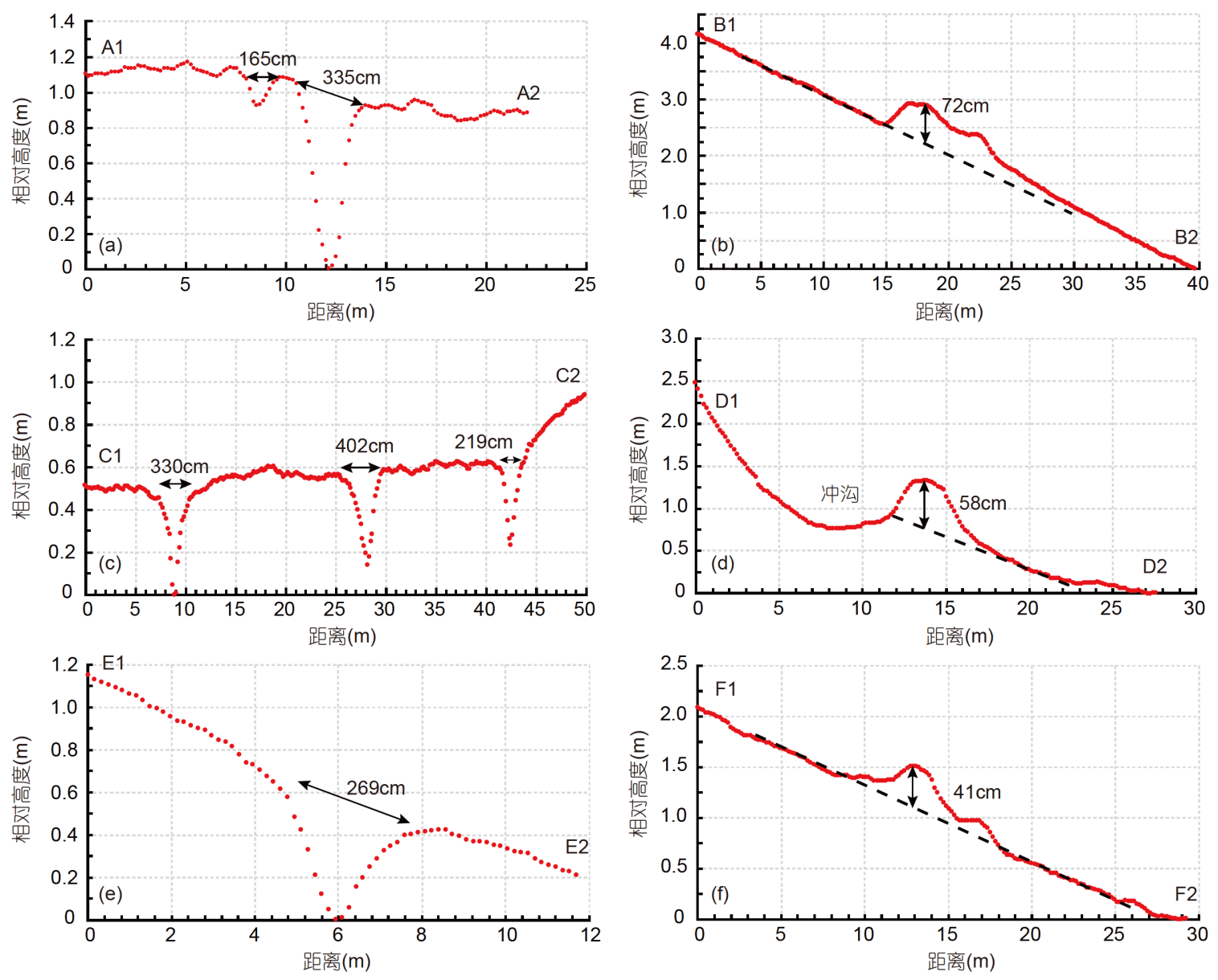

图 7 南段S1部分裂缝及剪切挤压脊地形剖面

位置见图6(b)

14c 14h). 其中挤压构造既有较为陡立的线性挤压脊, 也有较缓的褶皱，垂向变形可达 $0.8 \mathrm{~m}$. 个别地方可见 剪切变形, 如横跨三条褶皱陡坎的车辙分别被左旋位 错了106、72和67cm(图13a). 地堑系宽度从十几米至 百米不等, 垂向位移可达 $1 \mathrm{~m}$. 挤压变形均位于地堑系 前方(朝盐湖一侧), 应为拉张变形的响应. 这些变形构 造距离湖岸线均小于 $200 \mathrm{~m}$, 且总体沿着湖岸线平行展 布, 而南侧的地震地表破裂呈雁列式展布于山麓地带, 说明这些地堑系和挤压构造与深部断层无关.

\section{6 讨论}

\section{1 地震地表破裂带宽度与断裂几何结构的关系}

地震地表破裂带变形宽度与地震灾害有着密切的 关系, 如何预估断裂发生地震时的变形带宽度是防震
减灾的重要科学问题(Bryant, 2010; Zhou等, 2010). 有 震例研究表明, 地震地表破裂带宽度与主断裂的几何 结构密切相关(Treiman等, 2002; Choi等, 2018). 2014 年于田地震地表破裂也显示其地表破裂宽度与断裂几 何结构有着紧密的关系: 在弯曲和阶区部位, 破裂宽度 明显高于平直段(图4a), 尤其中段 $S 2$ 与南段 $S 1$ 交汇部 位, 破裂分布宽可达 $1.8 \mathrm{~km}$. 与其他两段相比, 中段 $\mathrm{S} 2$ 缺少主破裂, 且破裂宽度明显偏大. 这可能与中段 $\mathrm{S} 2$ 作 为与前两者走向共轭的阶区连接构造相关, 其发育程 度低和活动性弱, 主要作用是调节南硝尔库勒断裂与 阿什库勒断裂之间应变分配. 此外, 中段S2更靠近沉 积中心, 较厚的松散沉积物覆盖层在浅表放大了地震 破裂(见图2a). 尽管中段S2破裂宽度较宽导致位移相 对较小, 但是平均裂缝宽度也达到了 $36 \mathrm{~cm}$, 有些甚至 达到了1 2m, 其破坏性不容忽视. 

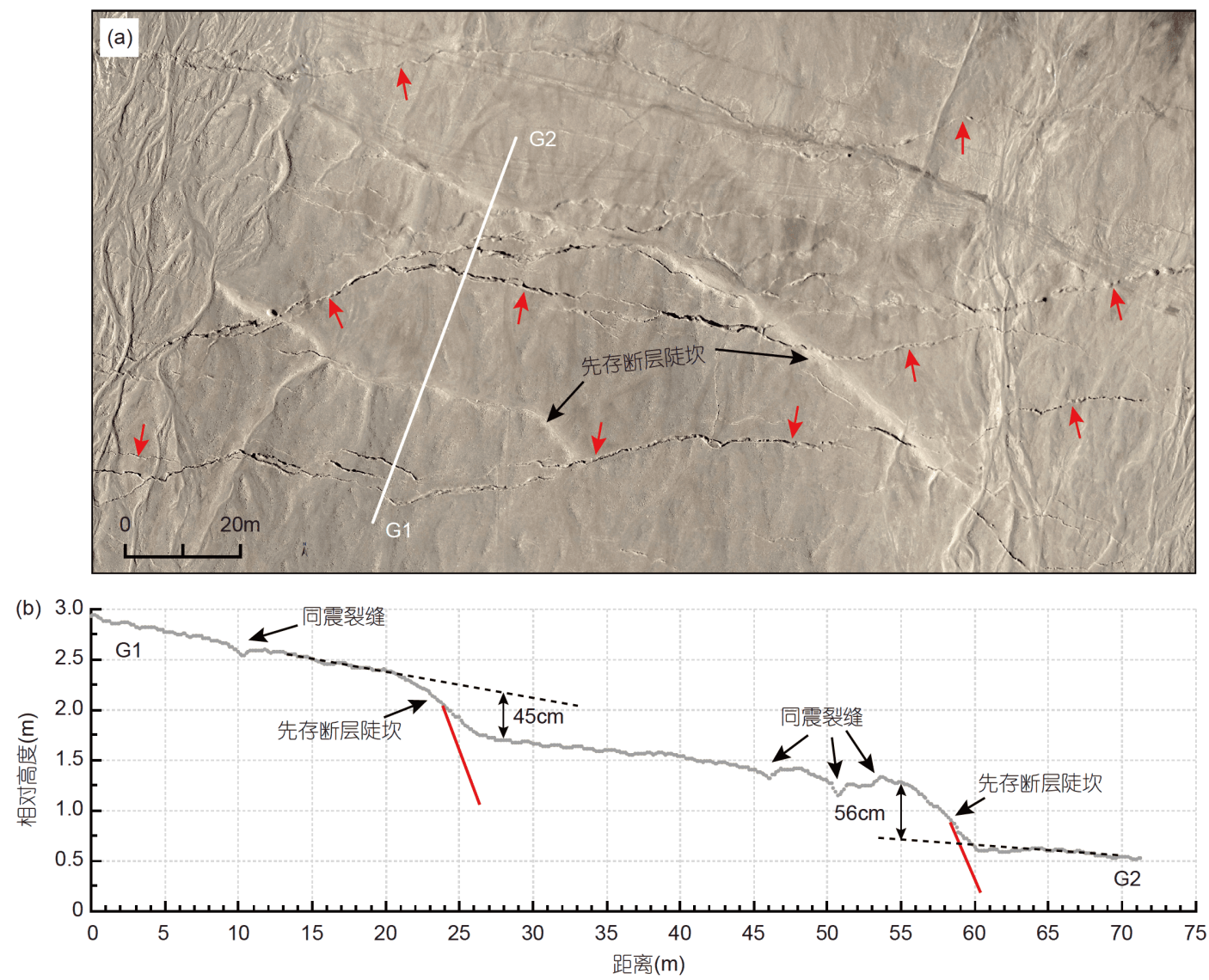

图 8 在中段 $\mathrm{S} 2$ 上分布的先存断层陡坎

(a) 同震张裂缝与先存断层陡坎相交, 显示先存断层陡坎在 2014 年地震中未破裂. 位置见图 $3(\mathrm{c})$, 红色箭头所指为张裂缝, 白色实线表示地形剖 面位置, 底图为无人机正射影像; (b) 地形剖面, 先存断层陡坎高度为 $45 \sim 56 \mathrm{~cm}$

为了进一步揭示走滑断裂同震破裂分布与断裂复 杂几何结构的关系，本文统计了10例全球走滑型地震 的破裂带宽度(见表1). 这些震例均具有详细地震地表 破裂展布图, 便于获得破裂展布范围. 统计结果显示在 断裂交汇处或与分支断裂围限区域、阶区、弯曲等几 何部位, 地表破裂宽度可达 $0.8 \sim 10 \mathrm{~km}$; 在平直段, 除了 1905年蒙古车车尔勒格-布内地震地表破裂宽度小于 $2 \mathrm{~km}$ 外, 其他震例破裂宽度均小于 $1 \mathrm{~km}$; 每个震例均显 示几何复杂部位的破裂宽度大于平直段. 在弯曲部位 破裂带宽度的增大与二维有限元数值模拟结果相吻 合，即塑性应变在断裂走向发生变化的转弯部位容易 形成条带状聚集，可能对应了密集发育的分布式地表 破裂(Duan和Day，2008)。此外，在具有拉张环境的部 位，破裂宽度的变大也与三维有限元数值模拟结果相 吻合, 即在浅地表因围压降低而广泛发育的屈服变形
(具体表现为分布式破裂)更容易发生在伸展区 $(\mathrm{Ma}$ 和 Andrews, 2010). 除了断裂几何结构外, 浅表的岩性也 可能影响破裂带宽度, 如 2010 年厄尔梅尔-库帕卡地震 和2014年于田地震平直段在基岩区的破裂宽度明显小 于冲洪积扇覆盖区域. 于田地震震区是青藏高原内流 区，以硝尔库勒湖为基准，从周围山地侵蚀区的物质 就近搬运, 形成从冲洪积相过渡到湖相的较厚松散沉 积盖层. 因此，于田地震主破裂外围的分布式变形裂 缝的发育特征对具有巨厚第四系沉积的华北平原地区 的地震地表破裂宽度有重要的启发意义.

综上所述，断裂几何复杂部位的地震地表破裂宽 度大于平直段，同时地层岩性也影响地表破裂宽度， 即在松散沉积物覆盖区比较宽，而在基岩区比较窄. 另外，这种宽变形带的位移也不容忽视，已有研究表 明分布式地表变形能占到地震地表破裂总位移的约 

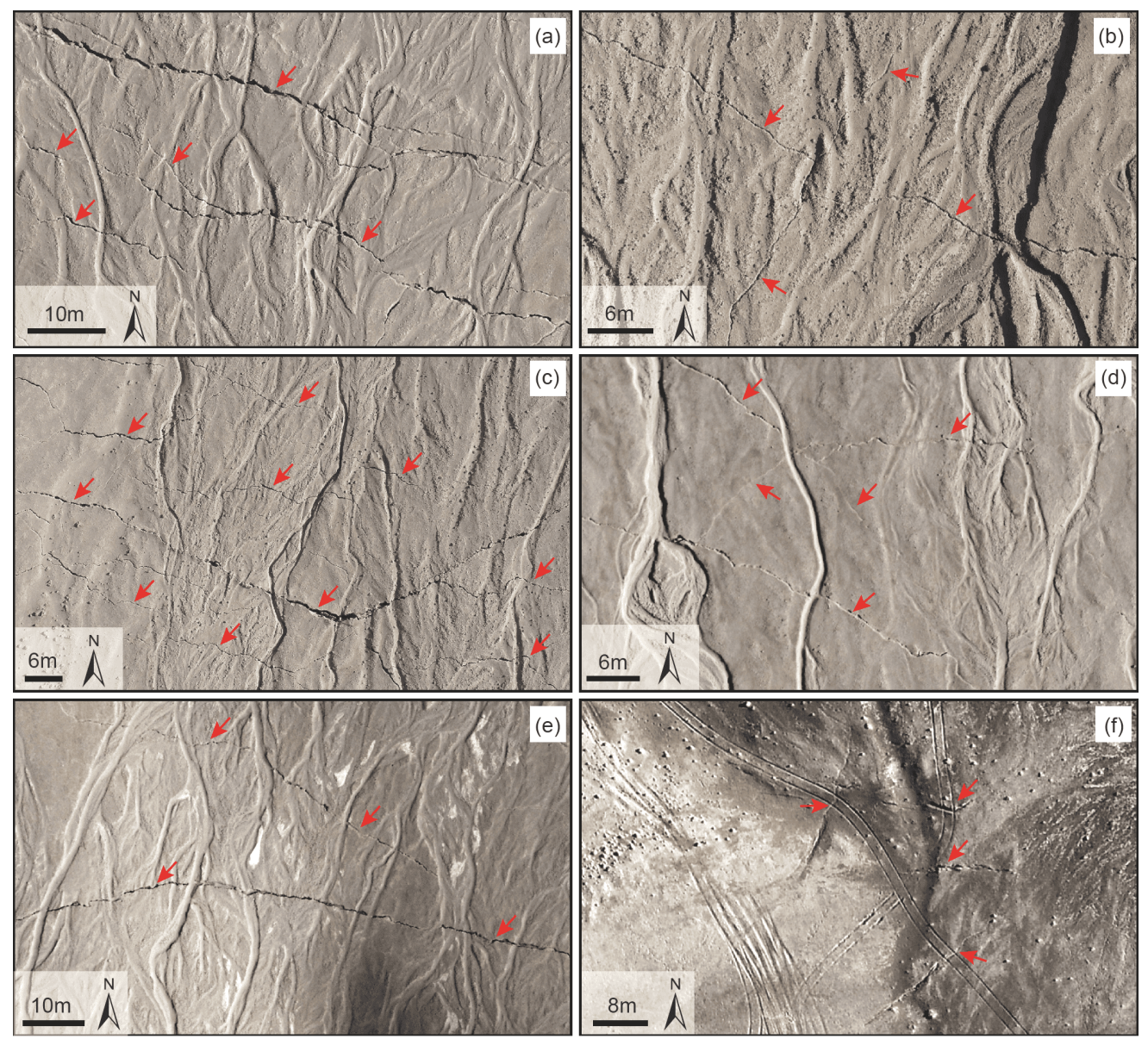

图 9 中段S2张裂缝正射航拍图

位置见图3(c) 和3(d), 红色箭头指向裂缝. 六个位置均未见冲沟、车辙等标志线的水平断错

15 46\%(Rockwell等，2002；Zinke等，2014；Gold等， 2015; Milliner等, 2015). 此次于田地震和2001年昆仑 山地震均已表明有些分布式破裂不具有原地重复破裂 的特征(徐锡伟等，2008). 因此，在工程建设中进行活 动断层避让时，需要额外考虑断裂几何结构和岩性对 避让距离的影响以及分布式破裂位置的复杂性. 另外, 在活动断层大比例尺填图中，也要注意识别断裂几何 复杂部位.

\section{2 级联破裂组合}

除了简单的单条断裂破裂之外，多条断裂参与破 裂的地震实例也越来越多，表明了地震破裂扩展的复 杂性，如1992年加州兰德斯 $M_{\mathrm{w}} 7.3$ 地震、2001年昆仑 山 $M_{\mathrm{w}} 7.9$ 地震、 2002 年阿拉斯加德纳里 $M_{\mathrm{w}} 7.9$ 地震以 及2016年新西兰凯库拉 $M_{\mathrm{w}} 7.8$ 地震等均有多条断裂同
时参与了破裂(Sieh等，1993；Xu等，2006；EberhartPhillips等, 2003; Hamling等, 2017). 同样, 2014年于田 地震也展现了这种破裂复杂性，即南硝尔库勒断裂 $(\mathrm{S} 1)$ 、硝尔库勒断裂 $(\mathrm{S} 2)$ 和阿什库勒断裂 $(\mathrm{S} 3)$ 等三条 断裂同时参与了破裂. 为了评价研究区可能的断裂破 裂图像，将依据断裂断错地貌特征和几何结构对研究 区内主要发育的康西瓦断裂、阿什库勒断裂和南硝尔 库勒断裂的破裂组合进行讨论.

在盐湖西侧，虽然阿什库勒断裂在2014年于田地 震中的左旋位错小于 $1 \mathrm{~m}$ ，但在地貌上保留了清晰的地 震地表破裂和累积位错冲沟(图15a和15b). 继续往两 侧追索，发现同等清晰度的地表破裂西至硝尔库勒盆 地西边界 $\left(82.298942^{\circ} \mathrm{E}, 36.030796^{\circ} \mathrm{N}\right)$, 东至与康西瓦 断裂相交处, 全长 $87 \mathrm{~km}$. 此段阿什库勒断裂地表几何 结构简单, 比较平直, 未发育可以阻碍破裂扩展的不连 

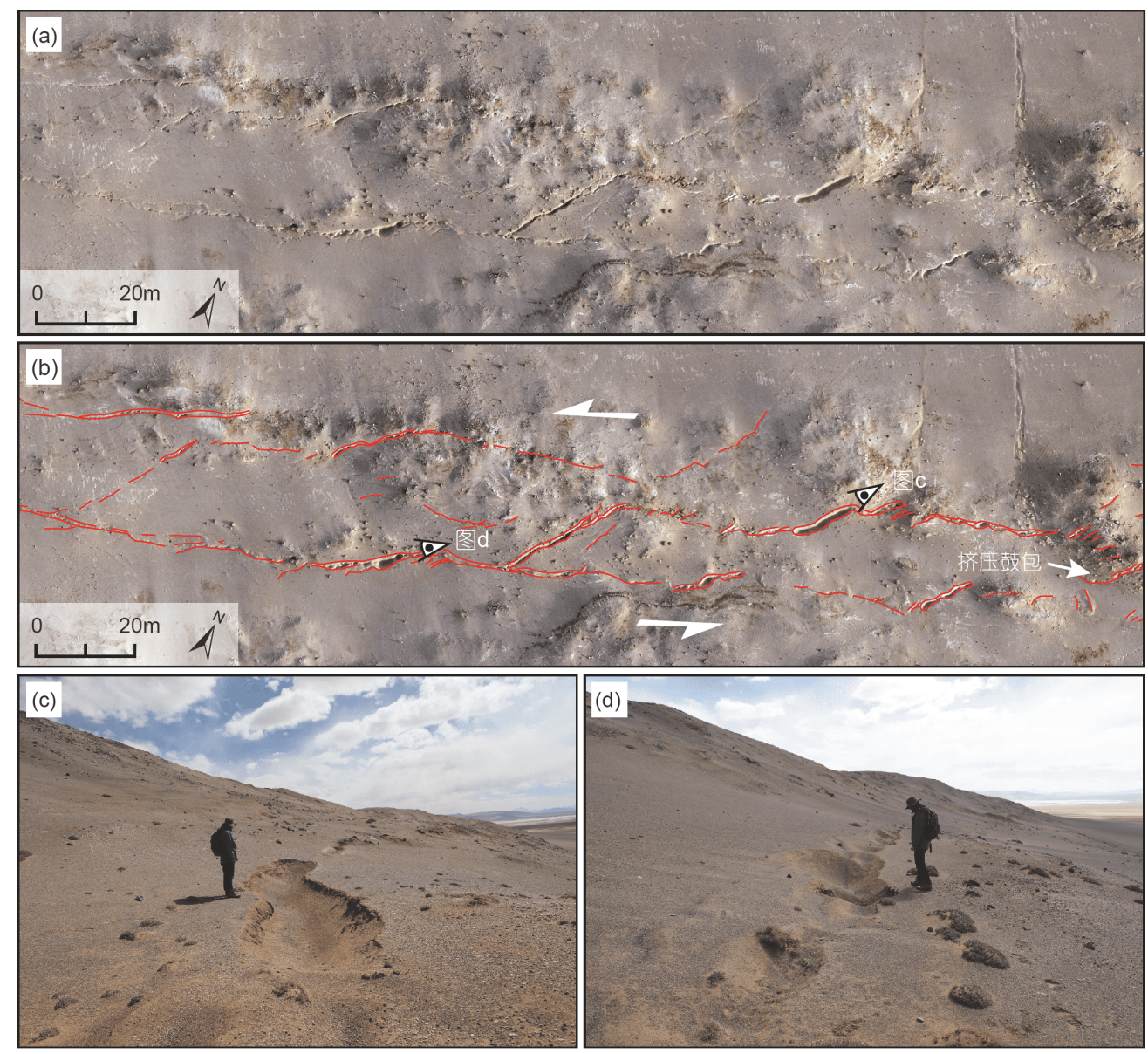

图 10 北段S3典型地表破裂

北段 $\mathrm{S} 3$ 典型左旋张剪切破裂(a)及其解译图(b), 底图为无人机正射影像, 位置见图 $3(\mathrm{f})$. (c) (d) 张剪切裂缝, 水平拉张宽度可达 $2 \mathrm{~m}$

续大型阶区和大角度大型弯曲等障碍体构造(Wesnousky, 2006; Lozos等, 2011), 表明该段地表破裂可能 是一次地震产生的. 根据地表破裂长度和震级之间的 关系(Wells和Coppersmith, 1994), 计算的震级可达 $M_{\mathrm{w}}$ (7.3 \pm 0.3$)$. 在南硝尔库勒断裂上, 未发现除2014年地震 地表破裂之外的与阿什库勒断裂清晰度类似的先存地 表破裂，表明南硝尔库勒断裂可能未参与阿什库勒断 裂上的破裂. 但是，也存在另外一种可能性，南硝尔库 勒断裂也参与了破裂, 只是产生的同震位错比较小, 而 且已经被完全改造掉. 如果阿什库勒断裂与南硝尔库 勒断裂发生级联破裂, 那么破裂长度可达 $103 \mathrm{~km}$, 震级 为 $M_{\mathrm{w}}(7.4 \pm 0.3)$ (Wells 和Coppersmith, 1994). 总之, 阿什 库勒断裂上先存地震地表破裂的规模远比2014年地震 产生的要大，表明2014年于田地震可能不是一个特征 性地震。
康西瓦断裂为硝尔库勒盆地主控断裂，在规模上 要比其他边界断裂大得多, 活动性更强, 具备发生更 强地震的能力(付碧宏等, 2006; Li 等, 2012). 在盐湖北 侧山麓地带, 亦可见保存清晰的地震地表破裂遗迹(图 $15 \mathrm{c})$. 该破裂带向西终止于硝尔库勒盆地西侧 $\left(82^{\circ} 15^{\prime}\right.$ $\left.51.77^{\prime \prime} \mathrm{E}, 36^{\circ} 9^{\prime} 11.02^{\prime \prime} \mathrm{N}\right)$, 向东终止于康西瓦断裂和阿 什库勒断裂交汇部位，全长 $~ 90 \mathrm{~km}$ ，震级可达 $M_{\mathrm{w}}(7.3$ \pm 0.3 )(Wells和Coppersmith，1994). 康西瓦断裂上的最 新地表破裂带与阿什库勒断裂上发现的地震地表破裂 是否可能为一次地震产生的呢? 假定两条断裂发生了 级联破裂，那么破裂总长度可达 $177 \mathrm{~km}$. 根据地表破 裂长度、同震位错和震级的关系式(Wells和Coppersmith, 1994), 那么震级可达 $M_{\mathrm{w}}(7.7 \pm 0.3)$, 产生的最大同 震位移和平均同震位移分别为 8.3 和 $~ 4.3 \mathrm{~m}$, 与我们观 察到的 5 和 $6 \mathrm{~m}$ 的左旋位错相当(图15a和 $15 \mathrm{c}$ ). 因此，康 

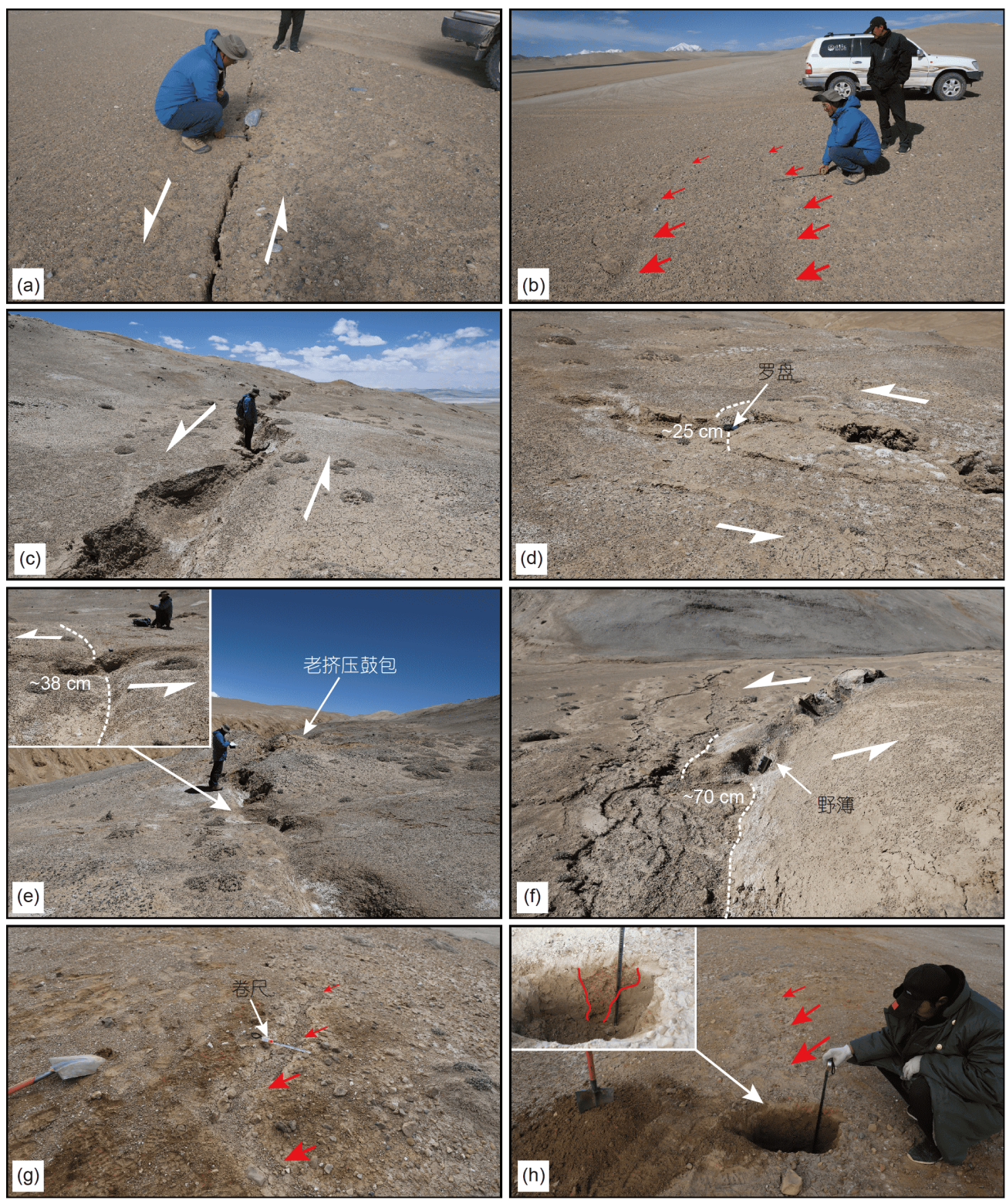

图 11 北段S3地表破裂

位置见图3(e) 3(g), 红色箭头指向裂缝. (a) S3西端小型裂缝, 宽度仅为几公分; (b) 几乎被完全填充的裂缝; (c) 左旋张剪切裂缝, 镜向 SW; (d) 被左旋断错的草堆; (e) 左旋张剪切裂缝, 可见小型冲沟被左旋 $38 \mathrm{~cm}$, 并切穿了老挤压鼓包, 镜向 $\mathrm{NE}$; (f) 沟壁被左旋位错 $70 \mathrm{~cm}$, 镜向 SE; (g) 被部分充填的裂缝; (h) 开挖的裂缝, 可见裂缝内充填沉积物与两壁不同

西瓦断裂和阿什库勒断裂既有单独破裂的可能性，也 有级联破裂的可能性.

尽管从整体地形上看，南硝尔库勒断裂是硝尔库 勒盆地的控盆断裂，地震破裂基本沿山体与冲洪积扇 的分界线展布，但是整个山麓地带未见地貌面的累积 左旋位错，而且2014年于田地震主地表破裂带通过的 基岩区，也未见清晰显著的山脊沟谷的左旋位错。该
现象与阿什库勒断裂以及康西瓦断裂形成了鲜明对 比, 后者发育了典型的走滑位错地貌. 因而推断南硝尔 库勒断裂的地震复发周期可能较长，或主要以较小的 左旋走滑位移，位错地貌在地震间歇期内被地表作用 改造掉. 总之, 位错地貌的清晰程度显示康西瓦断裂 和阿什库勒断裂的活动性强于南硝尔库勒断裂, 而且 在更早的地震事件中, 南硝尔库勒断裂是否与阿什库 

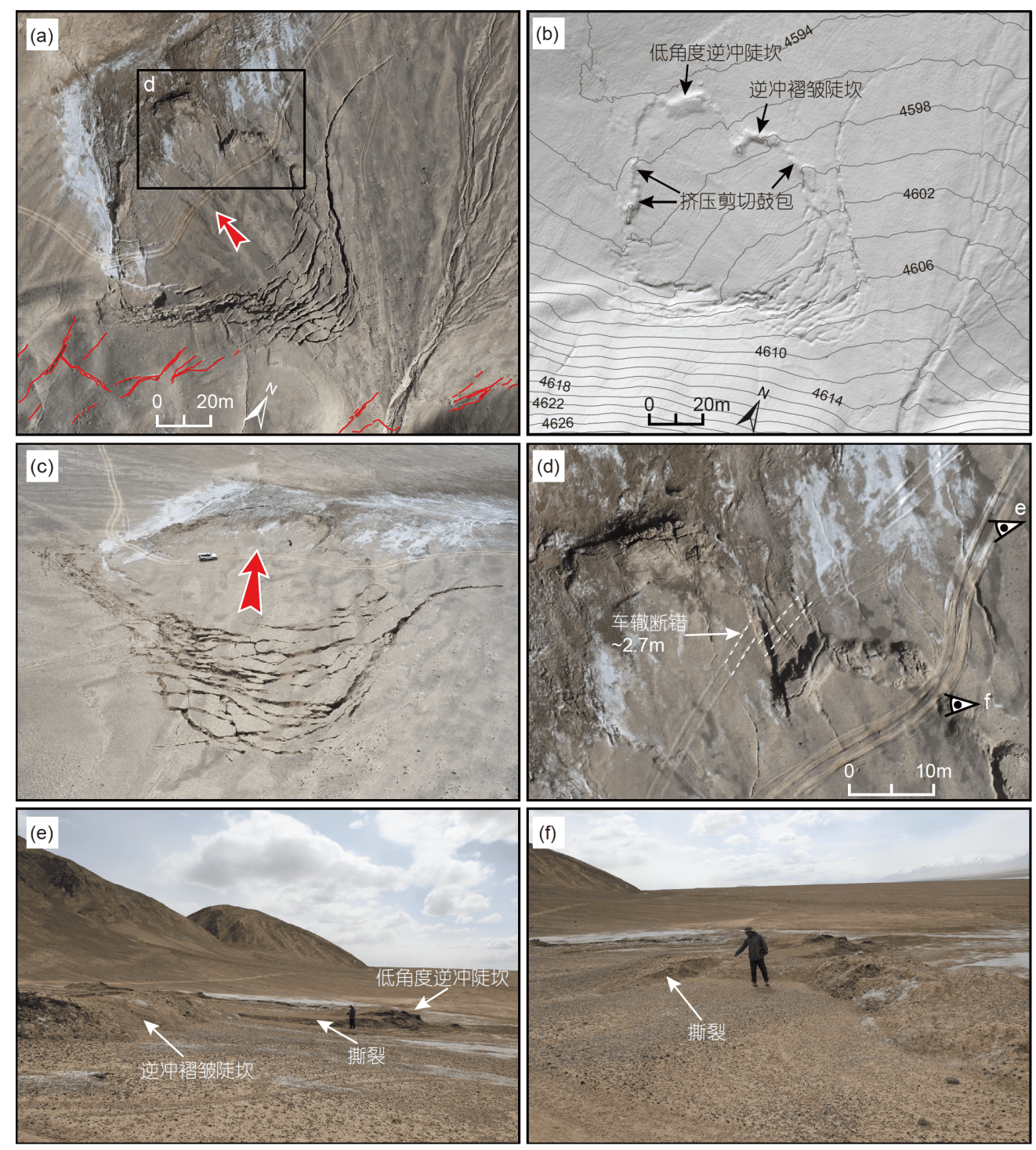

图 12 滑坡体L1

(a) 滑坡体正射航拍图; (b) 滑坡体山影图, 等高线数值单位为 $\mathrm{m}$, 间距为 $2 \mathrm{~m}$; (c) 无人机斜射航拍图, 镜向 NW; (d) 撕裂产生的右旋断错车辙; (e) （f) 滑坡体前缘逆冲构造, 镜向为SWW. 位置见图3(c)

勒断裂产生级联破裂尚不明确，而康西瓦断裂和阿什 库勒断裂既有单独破裂, 又有级联破裂的可能.

\section{3 滑坡和地堑系的滑动模式}

地震触发的滑坡受多种因素控制，如岩性、坡 度、坡向、距断层或震中以及水体的距离等(Keefer, 2000；Tian等，2017；Massey等，2018；Valagussa等， 2019). 2014年于田地震产生的两处滑坡体前缘均在盐 湖湖岸线上(图12a和13a), 表明滑坡体下部的地下水水
位较浅. 此外, 盐湖内部发育了大量盐丘构造, 而且湖 岸线均分布大量的白色盐晶(图12a和13a). 所以，推测 滑坡体下部的滑脱层应该为含水的盐层. 在地震震动 效应下，含水的盐层压力增加，降低了滑脱面的强度, 致使扇体失稳，后因重力作用往下滑动，形成滑坡(图 16). 这种成因模式也适用于洪积扇上发育的大量地堑 系. 因此, 除了防范断层的直接错动、基岩滑坡以及砂 土液化等产生的灾害外，也要注意发育在坡度较缓冲 洪积扇上的低角度滑坡带来的危险，尤其是地下水位 

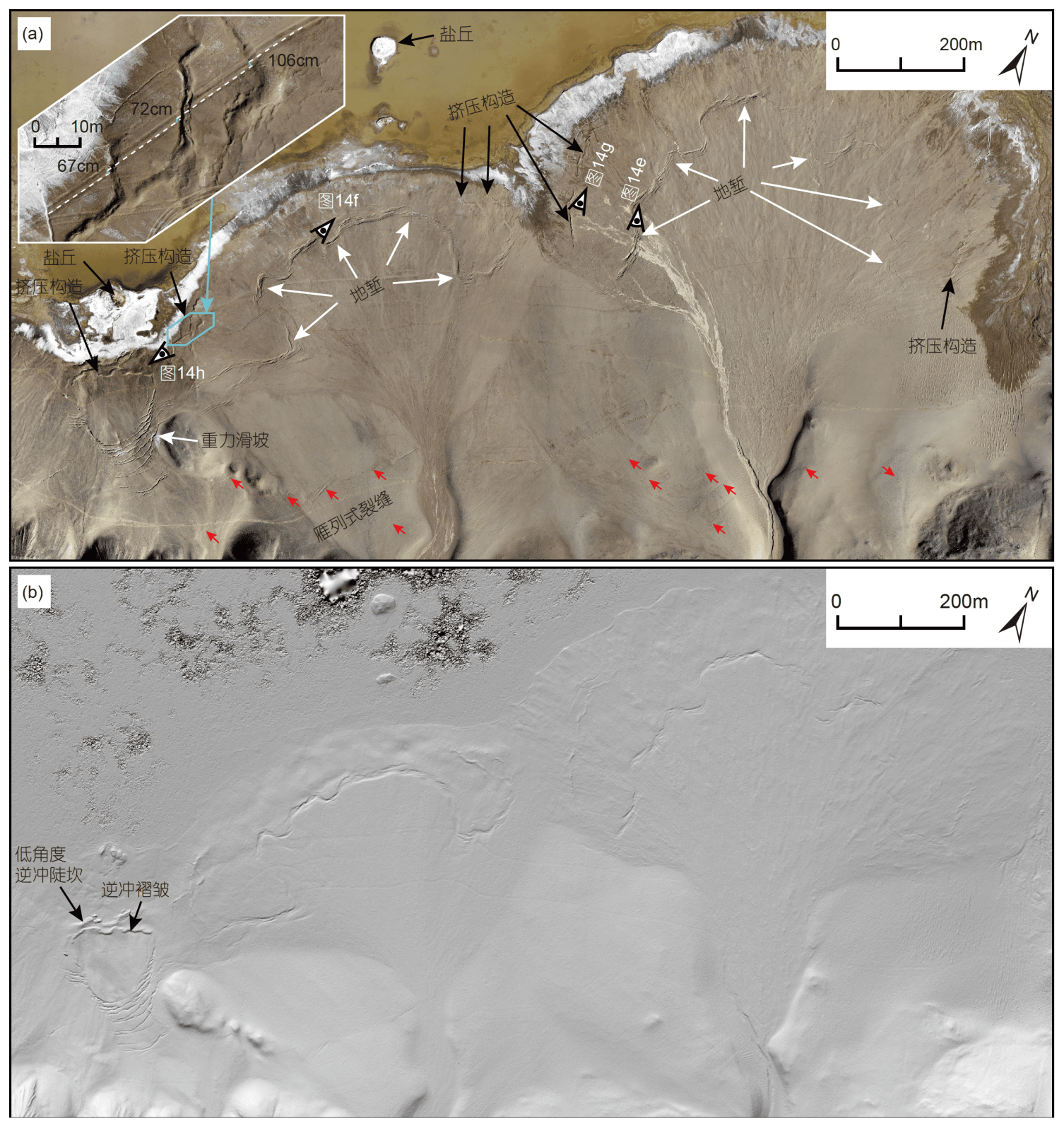

图 13 滑坡体L2、地堑系及挤压构造分布图

(a) 正射镶嵌航拍影像, 位置见图3(c); (b) 山影图, 滑坡体L2、地堑系和挤压构造均能显示. 红色箭头指向地震地表破裂

较浅, 又距离断层较近的冲洪积扇. 这种低缓洪积扇的 失稳滑动模式及其形成的破裂样式与被动型大陆边缘 三角洲中发育的重力滑脱构造极其相似。前者破裂样 式表现为滑坡体后缘的密集型拉张裂缝，前缘表现为 褶皱、低角度逆冲陡坎，前缘两侧发育挤压剪切隆起， 而且由于挤压缩短的差异而形成撕裂构造. 后者表现 为近端拉张和远端缩短，即三角洲顶部的正断层拉张 和深水区的褶皱逆冲带，且这种变形下部存在一个由
页岩或盐层组成的滑脱层(Rowan等，2004；King等， 2010).

6.4 于田地震破裂过程与断裂地表几何结构的耦 合关系

地震破裂在传播扩展过程中在断裂走向突然改变 的位置会突然增速或降速，释放高频地震波能量(Madariaga, 1977). 换句话说, 地震破裂扩展过程与断裂几 

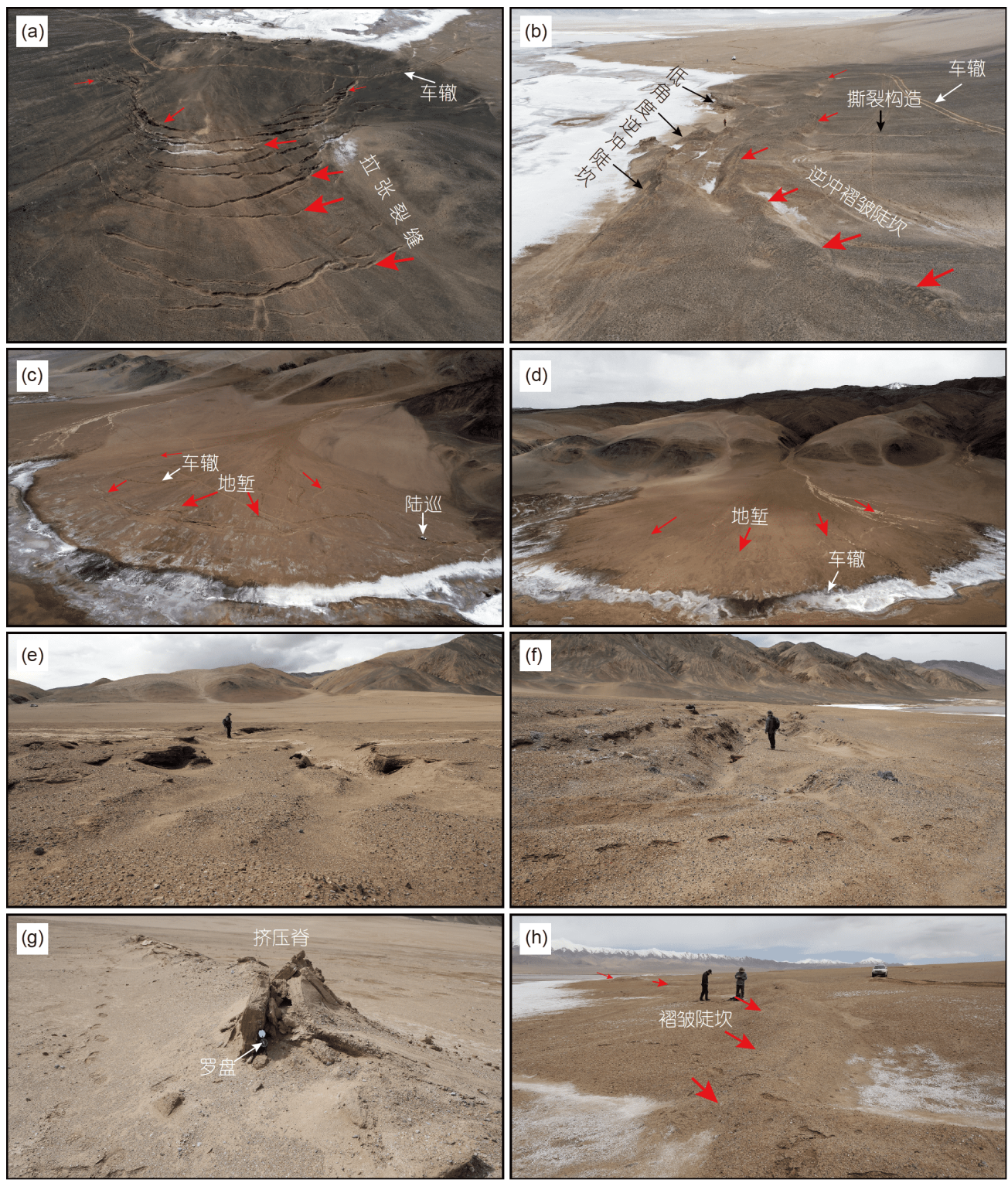

图 14 滑坡体L2、地堑系和挤压构造

(a) 滑坡体L2斜射航拍影像, 镜向NW; (b) 滑坡体前缘挤压变形构造以及撕裂构造, 镜像NEE; (c) (d) 洪积扇地堑分布斜射航拍影像, 镜向 SE; (e) (f) 地堑, 镜向S, 位置见图13(a); (g) 较陡的挤压脊, 镜向 $\mathrm{S}$, 位置见图13(a). (h) 较缓的逆冲福铍陡坎, 镜向N, 位置见图13(a)

何结构具有密切的相关性，具体表现为地表变形的分 布特征. Zhang和 Ge(2017)综合利用反投影远震P波方 法和线性有限元断层模拟方法探讨了2014年于田地震 破裂方向和过程(图17)：地震破裂往震中NE方向以 $\sim 1.6 \mathrm{~km} \mathrm{~s}^{-1}$ 的速率传播扩展了 $20 \mathrm{~s}$ ，向 $\mathrm{SW}$ 方向以 $\sim 1.3 \mathrm{~km} \mathrm{~s}^{-1}$ 扩展了 $\sim 14 \mathrm{~s}$; 往NE破裂传播，在第 $\sim 5 \mathrm{~s}$ 时到 达了 SF2 与 $\mathrm{SF} 1$ 相交位置, 释放了大量的高频地震波能 量; 继续向 $\mathrm{NE}$ 破裂扩展，在第 $7 \mathrm{~s}$ 时遇到阶区 $(\mathrm{SF} 1$ 与
SF3相交位置)，破裂速度突然降低，释放了最多的高 频地震波能量; 然后，破裂通过阶区(SF3)，第 9s时在 阶区北侧 (SF3 与 SF4相交位置) 速度继续下降, 释放了 高频地震波能量; 跨过阶区后, 地表破裂继续沿着 SF4 往NE方向扩展. 此外, 地震破裂沿着SF2向西扩展, 到 达与阿什库勒断裂相交位置, 也释放了较多的高频地 震波能量.

此次于田地震发育了三处比较突出的地表变形: 
表 1 全球陆地走滑型地震几何复杂部位地表破裂带宽度统计表 ${ }^{a)}$

\begin{tabular}{|c|c|c|c|c|c|c|}
\hline 年份 & 地震位置 & 震级 & $\begin{array}{c}\text { 几何复杂部位破 } \\
\text { 裂带宽度(km) }\end{array}$ & 位置描述 & $\begin{array}{c}\text { 平直段破裂带最大 } \\
\text { 宽度 }(\mathrm{km})\end{array}$ & 参考文献 \\
\hline 1872 & 欧文谷(Owens Valley) & $M_{\mathrm{w}} \geq 7.5$ & $3.7 、 3.5$ & $\begin{array}{l}\text { 阶区, 分支断裂与主 } \\
\text { 断裂围限区域 }\end{array}$ & 0.2 & Bryant等(2002) \\
\hline 1905 & $\begin{array}{c}\text { 车车尔勒格-布內(Tsetserleg- } \\
\text { Bulnay) }\end{array}$ & $M \geq 8$ & $6.7 、 3.4 、 2.0$ & 断裂交汇处 & 2 & Choi等(2018) \\
\hline 1968 & 博雷戈山(Borrego Mountain) & $M 6.6$ & 1.3 & 阶区 & 0.18 & Treiman等(1999) \\
\hline 1987 & $\begin{array}{c}\text { 爱尔摩牧场-迷信山(Elmore } \\
\text { Ranch-Superstition Hills) }\end{array}$ & $M_{\mathrm{s}} 6.2, M_{\mathrm{s}} 6.6$ & 10.0 & 断裂交汇处 & 0.36 & Hudnut等(1989) \\
\hline 1992 & 兰德斯(Landers) & $M_{\mathrm{w}} 7.3$ & $2.9 、 3.9$ & 阶区 & 0.29 & $\begin{array}{l}\text { Zachariasen和Sieh } \\
\text { (1995); Spotila和Sieh } \\
\text { (1995) }\end{array}$ \\
\hline 1999 & 赫克托矿(Hector Mine) & $M_{\mathrm{w}} 7.1$ & 0.8 & 阶区 & 0.08 & Treiman等(2002) \\
\hline 2001 & 昆仑山 & $M_{\mathrm{w}} 7.9$ & 2.8 & 两条断裂之间的区域 & 0.03 & 徐锡伟等(2008) \\
\hline 2010 & $\begin{array}{c}\text { 厄尔梅尔-库卡帕(E1 Mayor- } \\
\text { Cucapah) }\end{array}$ & $M_{\mathrm{w}} 7.2$ & 1.0 & 阶区 & $\begin{array}{c}0.43 \text { (冲洪积扇), } \\
0.06 \text { (基岩区) }\end{array}$ & Teran等(2015) \\
\hline 2014 & 于田 & $M_{\mathrm{w}} 6.9$ & 1.8 & 断裂交汇处 & $\begin{array}{l}\text { 1(冲洪积扇), } \\
0.13 \text { (基岩区) }\end{array}$ & 本研究 \\
\hline 2016 & 凯库拉(Kaikōura) & $M_{\mathrm{w}} 7.6$ & $0.8 、 2.0$ & 断裂交汇处, 弯曲 & 单条断层, 0.1 & $\begin{array}{c}\text { Langridge等(2018, } \\
\text { 2016) }\end{array}$ \\
\hline
\end{tabular}

a) 在文献中, 凯库拉地震地表破裂带平直段破裂仅为单条断层, 猜测其破裂宽度小于 $0.1 \mathrm{~km}$

第一处为南段与中段相交区域，发育了密集的大量网 格状地表裂缝，也是中段最大拉张量分布区; 第二处, 在南段东端洪积扇发生了大量失稳，形成了两处滑坡 和密集的地堑系，同时也是南段最大拉张位置; 第三 处, 在北段SW端附近发育了大量分布式地表裂缝, 也 是北段破裂范围最大位置. 这三处地表变形加剧的地 方正是断裂几何结构的复杂部位，也是释放大量高频 地震波能量的位置. 所以地表变形加剧除了受岩性影 响之外，还与高频地震波产生更强的地震动有关. 另 外，中段西端尾部与阿什库勒断裂走向一致的地表破 裂表明破裂以硝尔库勒断裂(SF2)为桥梁传播到阿什 库勒断裂后, 可能沿该断裂往南西方向持续破裂, 与另 一支从 SF3到SF4北东向破裂传播反向. 地表填图一方 面印证了 Zhang和 Ge(2017)破裂后期SW方向扩展的 反演结果，同时暗示SW方向扩展的破裂发生在阿什 库勒断裂的深部, 而Zhang和 Ge(2017)反演的分辨率无 法区分SW向破裂发生在阿什库勒断裂还是南硝尔库 勒断裂上，表明地震地表破裂的调查可以为理解破裂 动态过程提供重要约束. 因此, 于田地震破裂扩展过 程与断裂几何结构存在直接的耦合关系，且地表变形 样式是这种关系的直接响应.

\section{7 结论}

通过详细解译高分辨率无人机正射影像, 获得了 2014年于田 $M_{\mathrm{s}} 7.3$ 地震地表破裂精细展布图. 地震地表 破裂带共分为三段: 南段 $\mathrm{S} 1$, 呈 NE走向, 长 $16 \mathrm{~km}$; 中段 $\mathrm{S} 2$, 呈近 $\mathrm{EW}$ 走向，长6.9 km; 北段 $\mathrm{S} 3$, 呈 $\mathrm{NE}$ 走向，长 $14.2 \mathrm{~km}$. 南段和北段大部分地表破裂显示张剪切性质; 中段以张性破裂为主，主要表现为EW和NS两组张裂 缝. 南段平均左旋位错和平均拉张量分别为 $(52 \pm 25) \mathrm{cm}$ 和(3.4 \pm 2.9$) \mathrm{m}$; 北段平均左旋位错和平均拉张量分别为 $(36 \pm 21) \mathrm{cm}$ 和 $(1.7 \pm 1.6) \mathrm{m}$; 中段平均拉张量为 $(4.3 \pm 3.6)$ $\mathrm{m}$. 共统计了 5308 处裂缝宽度, 南段平均宽度为 $(85$ $\pm 71) \mathrm{cm}$ ，最宽可达 $700 \mathrm{~cm}$; 中段平均宽度为 $(39 \pm 21)$ $\mathrm{cm}$, 最宽可达 $243 \mathrm{~cm}$; 北段平均宽度为 $(61 \pm 44) \mathrm{cm}$, 最 大可达 $340 \mathrm{~cm}$. 南段 $\mathrm{S} 1$ 平均裂缝宽度和拉张量在弯 曲、阶区等断裂几何复杂部位具有减小的趋势，而破 裂分布宽度在这些几何复杂部位较大; 中段 $\mathrm{S} 2$ 的破裂 分布宽度可达 $1.8 \mathrm{~km}$, 其东段裂缝宽度变化不大, 西段 变化较大; 北段 $\mathrm{S} 3$ 裂缝宽度和平均拉张量具有向断裂 两端递减的趋势. 结合对全球走滑型地震地表破裂带 的统计发现，破裂分布范围与断裂几何结构、岩性等 


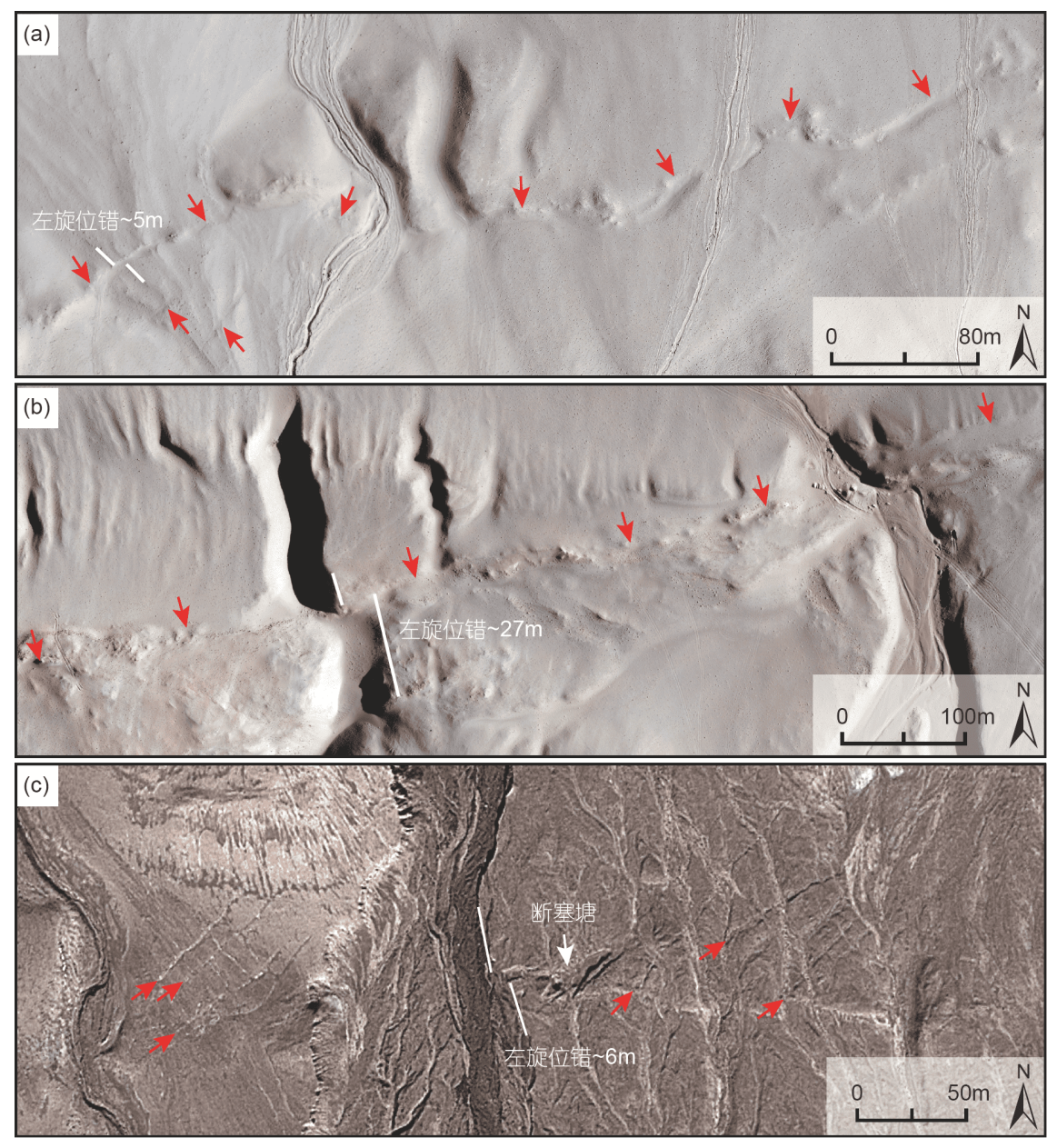

图 15 阿什库勒断裂和康西瓦断裂位错地貌

(a) 阿什库勒断裂最新一次地震地表破裂, 呈右阶雁列展布, 可见冲沟被左旋位错 $\sim 5 \mathrm{~m}$, 影像为无人机航拍, 具体位置见图 $3(\mathrm{a})$, 红色箭头指向地 表破裂, 下同. (b) 阿什库勒断裂累计左旋位错及地震地表破裂, 影像为无人机航拍, 位置见图3(a). (c) 硝尔库勒盐湖北侧康西瓦断裂最新地震 地表破裂, 发育了张剪切破裂及断塞塘, 冲沟东壁被左旋位错 $6 \mathrm{~m}$, 影像来自Google Earth, 位置 $82.642695^{\circ} \mathrm{E}, 36.174760^{\circ} \mathrm{N}$

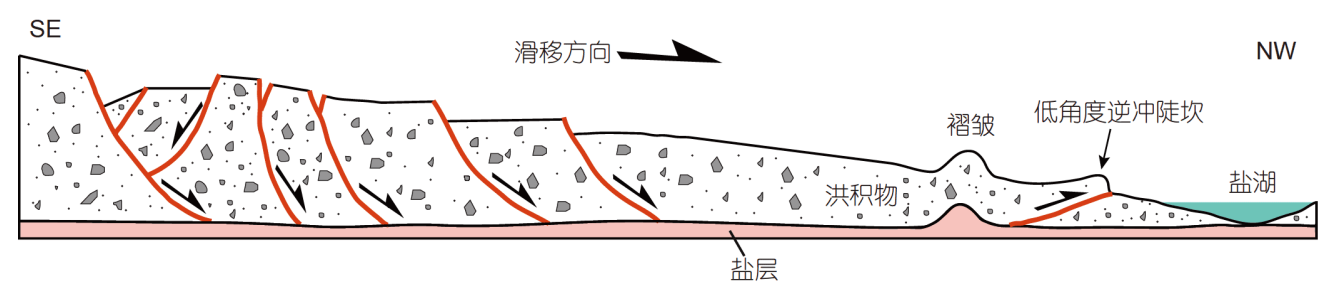

图 16 滑坡体滑动模式图

相关，即在断裂相交位置、弯曲和阶区位置以及在松 散沉积物覆盖区域，破裂范围更大，而在平直段和基 岩区较为集中．通过分析研究区三条断裂的地震地表 破裂遗迹发现，2014年于田地震可能不是一个特征性 地震，而在更早的地震事件中，阿什库勒断裂和康西
瓦断裂存在级联破裂或单独破裂的可能，而南硝尔库 勒断裂参与级联破裂的证据不足. 于田地震破裂带附 近，还发育大量的次生浅地表变形，与震区较厚的松 散沉积层和较浅的含水盐层相关. 于田地震地表变形 样式是地震破裂扩展过程与断裂几何结构耦合关系的 


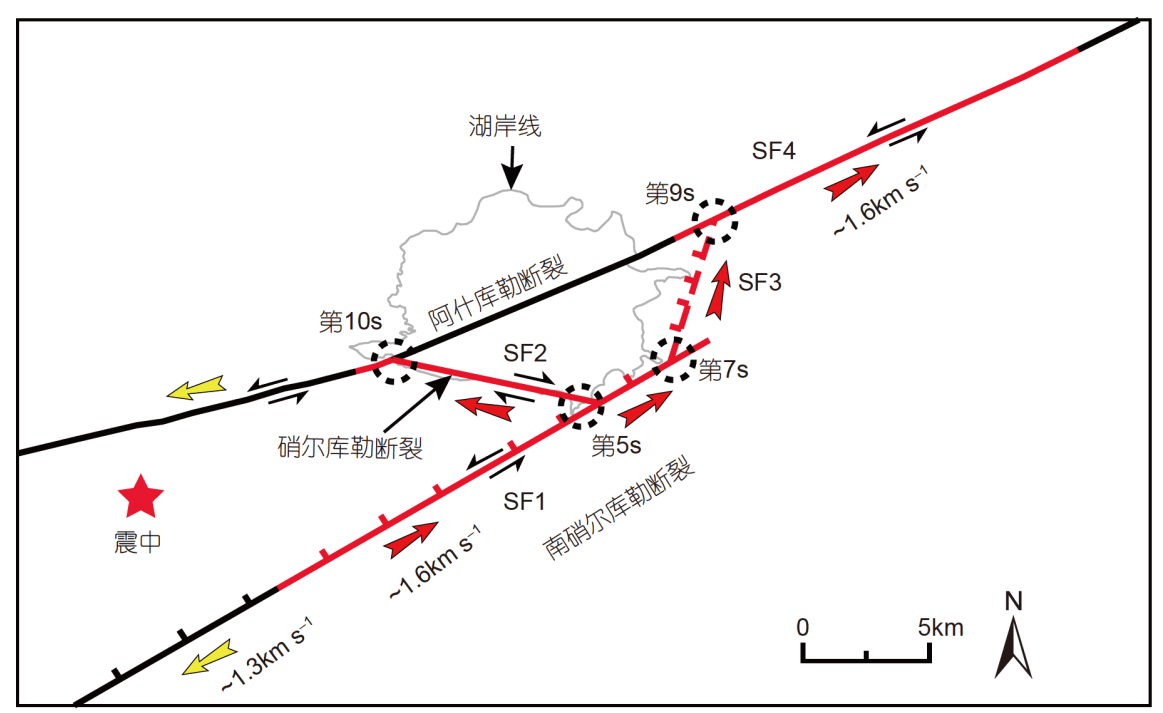

图 17 于田地震破裂扩展过程

$\mathrm{SF} 1$ 南段破裂段, SF2 中段破裂段, SF3阶区破裂段, SF4北段破裂段; 红色直线表示地表破裂段, 黑色直线表示地表未破裂段; 红色箭头表示地 表破裂扩展方向, 黄色箭头表示断裂深部破裂扩展方向; 虚线圆圈表示高频地震波能量在地表的释放位置

直接响应，地表破裂的详细调查可以为地震破裂动态 过程提供重要约束. 因此, 在评估断裂地震灾害时, 既 需要考虑断裂几何结构、岩性以及断裂级联破裂的可 能性, 也需要关注断裂附近与水体相邻的洪积扇产生 诱发重力滑动的影响.

致谢＼cjkstart感谢中国地震局地球物理研究所房立华研究员提 供的余震信息. 在论文写作中得到北京大学盖增喜、加 州大学圣塔芭芭拉分校纪晨和德州农工大学段本春等教 授关于地震破裂过程机理的有益讨论和启发，特此感谢 三位老师。感谢中国地震局地震预测研究所徐岳仁副研 究员提出的修改意见，也衷心感谢两位若名审稿专家提 出的宝贵修改意见, 提高了论文整体质量.

\section{参考文献}

陈杰, 陈宇坤, 丁国瑜, 田勤俭, 王赞军, 单新建, 任金卫, 赵瑞斌, 王

志才. 2003. 2001年昆仑山口西 8.1 级地震地表破裂带. 第四纪研

究, 23: 629-639

邓起东, 张培震, 由勇康, 杨晓平, 闵伟, 楚全芝. 2002. 中国活动构造

基本特征. 中国科学 $\mathrm{D}$ 辑: 地球科学, 32: 1020-1030

房立华, 吴建平, 王未来, 杨婷, 王长在. 2015. 2014年新疆于田 $M_{\mathrm{s}} 7.3$

级地震序列重定位. 地球物理学报, 58: 802-808

付碧宏, 张松林, 谢小平, 石许华, 王世锋. 2006. 阿尔金断裂系西段

——康西瓦断裂的晚第四纪构造地貌特征研究. 第四纪研究, 26:
$228-235$

顾功叙. 1983. 中国地震目录(公元前1831-公元1969). 北京: 科学出 版社. 894

国家地震局阿尔金活动断裂带课题组. 1992. 阿尔金活动断裂带. 北 京: 地震出版社. 319

国家地震局地质研究所, 宁夏回族自治区地震局. 1990. 海原活动断 裂带. 北京: 地震出版社. 286

李金, 王琼. 2015. 2014年2月12日于田7.3级地震序列震源机制特征 分析. 中国地震, 31: 114-124

闻学泽, 范军, 易桂喜, 邓一唯, 龙锋. 2008. 川西安宁河断裂上的地 震空区. 中国科学D辑: 地球科学, 38: 797-807

徐锡伟, 于贵华, 马文涛, 林传勇. 2008. 昆仑山地震 $\left(M_{\mathrm{w}} 7.8\right)$ 破裂行 为, 变形局部化特征及其构造内涵讨论. 中国科学 $\mathrm{D}$ 辑: 地球科 学, 38: 785-796

徐岳仁, 陈立泽, 申旭辉, 洪顺英, 王辉, 荆风, 董彦芳. 2015. 基于GF1 卫星影像解译2014年新疆于田 $M_{\mathrm{s}} 7.3$ 地震同震地表破裂带. 地 震, 35: 61-71

袁兆德, 刘静, 周游, 李志刚, 王恒, 姚文倩, 韩龙飞. 2019. 阿尔金断 裂中段乌尊硝尔段古地震记录与级联破裂行为. 中国科学: 地球 科学, 50: 50-65

Allen C R, Luo Z L, Qian H, Wen X Z, Zhou H W, Huang W S. 1991. Field study of a highly active fault zone: The Xianshuihe fault of southwestern China. Geol Soc Am Bull, 103: 1178-1199

Avouac J P, Tapponnier P. 1993. Kinematic model of active deformation in central Asia. Geophys Res Lett, 20: 895-898

Bemis S P, Micklethwaite S, Turner D, James M R, Akciz S, Thiele S 
T, Bangash H A. 2014. Ground-based and UAV-Based photogrammetry: A multi-scale, high-resolution mapping tool for structural geology and paleoseismology. J Struct Geol, 69: 163-178

Bi H Y, Zheng W J, Ren Z K, Zeng J Y, Yu J X. 2017. Using an unmanned aerial vehicle for topography mapping of the fault zone based on structure from motion photogrammetry. Int J Remote Sens, 38: $2495-2510$

Bryant W A. 2010. History of the Alquist-Priolo earthquake fault zoning act, California, USA. Environ Eng Geosci, 16: 7-18

Bryant W A, Sawyer T L, compilers. 2002. Fault number 51b, Owens Valley fault zone, 1872 rupture section. In: Quaternary Fault and Fold Database of the United States. U.S. Geological Survey website, https://earthquakes.usgs.gov/hazards/qfaults

Chevalier M L, Pan J W, Li H B, Sun Z M, Liu D L, Pei J L, Xu W, Wu C. 2017. First tectonic-geomorphology study along the LongmuGozha Co fault system, Western Tibet. Gondwana Res, 41: 411-424 Choi J H, Klinger Y, Ferry M, Ritz J F, Kurtz R, Rizza M, Bollinger L, Davaasambuu B, Tsend-Ayush N, Demberel S. 2018. Geologic Inheritance and earthquake rupture processes: The $1905 \quad M \geq 8$ Tsetserleg-Bulnay strike-slip earthquake sequence, Mongolia. J Geophys Res-Solid Earth, 123: 1925-1953

Cowgill E, Yin A, Harrison T M, Wang X F. 2003. Reconstruction of the Altyn Tagh fault based on U-Pb geochronology: Role of back thrusts, mantle sutures, and heterogeneous crustal strength in forming the Tibetan Plateau. J Geophys Res, 108: 2346

Duan B C, Day S M. 2008. Inelastic strain distribution and seismic radiation from rupture of a fault kink. J Geophys Res, 113: B12311

Eberhart-Phillips D, Haeussler P J, Freymueller J T, Frankel A D, Rubin C M, Craw P, Ratchkovski N A, Anderson G, Carver G A, Crone A J, Dawson T E, Fletcher H, Hansen R, Harp E L, Harris R A, Hill D P, Hreinsdóttir S, Jibson R W, Jones L M, Kayen R, Keefer D K, Larsen C F, Moran S C, Personius S F, Plafker G, Sherrod B, Sieh K, Sitar N, Wallace W K. 2003. The 2002 Denal fault earthquake, Alaska: A large magnitude, slip-partitioned event. Science, 300: 1113-1118

Elliott A J, Oskin M E, Liu-Zeng J, Shao Y X. 2015. Rupture termination at restraining bends: The last great earthquake on the Altyn Tagh Fault. Geophys Res Lett, 42: 2164-2170

Ferrario M F, Livio F. 2018. Characterizing the distributed faulting during the 30 October 2016, Central Italy earthquake: A reference for fault displacement hazard assessment. Tectonics, 37: 1256-1273

Gao M X, Xu X W, Klinger Y, Van der Woerd J, Tapponnier P. 2017. High-resolution mapping based on an Unmanned Aerial Vehicle (UAV) to capture paleoseismic offsets along the Altyn-Tagh fault, China. Sci Rep, 7: 8281

Gold R D, Reitman N G, Briggs R W, Barnhart W D, Hayes G P,
Wilson E. 2015. On- and off-fault deformation associated with the September $2013 M_{\mathrm{w}} 7.7$ Balochistan earthquake: Implications for geologic slip rate measurements. Tectonophysics, 660: 65-78

Gong Z J, Sun J M, Zhang Z L, Fu B H, Jia Y Y. 2017. Optical dating of an offset river terrace sequence across the Karakax fault and its implication for the late Quaternary left-lateral slip rate. J Asian Earth Sci, 147: 415-423

Hamling I J, Hreinsdóttir S, Clark K, Elliott J, Liang C, Fielding E, Litchfield N, Villamor P, Wallace L, Wright T J, D'Anastasio E, Bannister S, Burbidge D, Denys P, Gentle P, Howarth J, Mueller C, Palmer N, Pearson C, Power W, Barnes P, Barrell D J A, Van Dissen R, Langridge R, Little T, Nicol A, Pettinga J, Rowland J, Stirling M. 2017. Complex multifault rupture during the $2016 M_{\mathrm{w}} 7.8$ Kaikōura earthquake, New Zealand. Science, 356: eaam7194

Hudnut K, Seeber L, Rockwell T, Goodmacher J, Klinger R, Lindvall S, McElwain R. 1989. Surface ruptures on cross-faults in the 24 November 1987 Superstition Hills, California, earthquake sequence. Bull Seismol Soc Am, 79: 282-296

Keefer D K. 2000. Statistical analysis of an earthquake-induced landslide distribution-The 1989 Loma Prieta, California event. Eng Geol, 58: 231-249

King R C, Backé G, Morley C K, Hillis R R, Tingay M R P. 2010. Balancing deformation in NW Borneo: Quantifying plate-scale vs. gravitational tectonics in a delta and deepwater fold-thrust belt system. Mar Pet Geol, 27: 238-246

Klinger Y, Okubo K, Vallage A, Champenois J, Delorme A, Rougier E, Lei Z, Knight E E, Munjiza A, Satriano C, Baize S, Langridge R, Bhat H S. 2018. Earthquake damage patterns resolve complex rupture processes. Geophys Res Lett, 45: 10279-10287

Klinger Y, Xu X W, Tapponnier P, Van der Woerd J, Lasserre C, King G. 2005. High-resolution satellite imagery mapping of the surface rupture and slip distribution of the $M_{\mathrm{w}} 7.8,14$ November 2001 Kokoxili Earthquake, Kunlun Fault, Northern Tibet, China. Bull Seismol Soc Am, 95: 1970-1987

Langridge R M, Ries W F, Litchfield N J, Villamor P, Van Dissen R J, Barrell D, Rattenbury M S, Heron D W, Haubrock S, Townsend D B, Lee J M, Berryman K R, Nicol A, Cox S C, Stirling M W. 2016. The New Zealand active faults database. New Zealand J Geol Geophys, 59: 86-96

Langridge R M, Rowland J, Villamor P, Mountjoy J, Townsend D B, Nissen E, Madugo C, Ries W F, Gasston C, Canva A, Hatem A E, Hamling I. 2018. Coseismic rupture and preliminary slip estimates for the papatea fault and its role in the $2016 M_{\mathrm{w}} 7.8$ Kaikoura, New Zealand, Earthquake. Bull Seismol Soc Am, 108: 1596-1622

Li H B, Pan J W, Lin A M, Sun Z M, Liu D L, Zhang J J, Li C L, Liu K, Chevalier M L, Yun K. 2016. Coseismic surface ruptures associated 
with the $2014 M_{\mathrm{w}} 6.9$ Yutian Earthquake on the Altyn Tagh Fault, Tibetan Plateau. Bull Seismol Soc Am, 106: 595-608

Li H B, Van der Woerd J, Sun Z M, Si J L, Tapponnier P, Pan J W, Liu D L, Chevalier M L. 2012. Co-seismic and cumulative offsets of the recent earthquakes along the Karakax left-lateral strike-slip fault in western Tibet. Gondwana Res, 21: 64-87

Loveless J P, Meade B J. 2011. Partitioning of localized and diffuse deformation in the Tibetan Plateau from joint inversions of geologic and geodetic observations. Earth Planet Sci Lett, 303: 11-24

Lozos J C, Oglesby D D, Duan B C, Wesnousky S G. 2011. The effects of double fault bends on rupture propagation: A geometrical parameter study. Bull Seismol Soc Am, 101: 385-398

Ma S, Andrews D J. 2010. Inelastic off-fault response and threedimensional dynamics of earthquake rupture on a strike-slip fault. J Geophys Res, 115: B04304

Madariaga R. 1977. High-frequency radiation from crack (stress drop) models of earthquake faulting. Geophys J Int, 51: 625-651

Massey C, Townsend D, Rathje E, Allstadt K E, Lukovic B, Kaneko Y, Bradley B, Wartman J, Jibson R W, Petley D N, Horspool N, Hamling I, Carey J, Cox S, Davidson J, Dellow S, Godt J W, Holden C, Jones K, Kaiser A, Little M, Lyndsell B, McColl S, Morgenstern R, Rengers F K, Rhoades D, Rosser B, Strong D, Singeisen C, Villeneuve M. 2018. Landslides triggered by the 14 November 2016 $M_{\mathrm{w}} 7.8$ Kaikōura Earthquake, New Zealand. Bull Seismol Soc Am, 108: $1630-1648$

Massonnet D, Rossi M, Carmona C, Adragna F, Peltzer G, Feigl K, Rabaute T. 1993. The displacement field of the Landers earthquake mapped by radar interferometry. Nature, 364: 138-142

Meade B J. 2007. Present-day kinematics at the India-Asia collision zone. Geology, 35: 81-84

Milliner C W D, Dolan J F, Hollingsworth J, Leprince S, Ayoub F, Sammis C G. 2015. Quantifying near-field and off-fault deformation patterns of the $1992 M_{\mathrm{w}} 7.3$ Landers earthquake. Geochem Geophys Geosyst, 16: 1577-1598

Molnar P, Tapponnier P. 1975. Cenozoic tectonics of Asia: Effects of a continental collision: Features of recent continental tectonics in Asia can be interpreted as results of the India-Eurasia collision. Science, 189: 419-426

Moss R E S, Ross Z E. 2011. Probabilistic fault displacement hazard analysis for reverse faults. Bull Seismol Soc Am, 101: 1542-1553

Oskin M E, Arrowsmith J R, Hinojosa Corona A, Elliott A J, Fletcher J M, Fielding E J, Gold P O, Gonzalez Garcia J J, Hudnut K W, LiuZeng J, Teran O J. 2012. Near-field deformation from the El MayorCucapah earthquake revealed by differential LIDAR. Science, 335: 702-705

Pan J W, Li H B, Van der Woerd J, Sun Z M, Si J L, Pei J L, Wu F Y,
Chevalier M L. 2015. First quantitative slip-rate estimate along the Ashikule fault and tectonics of the westernmost segment of the Altyn Tagh fault. Acta Geol Sin-Engl Ed, 89: 2088-2089

Peltzer G, Brown N D, Mériaux A, Van der Woerd J, Rhodes E J, Finkel R C, Ryerson F J, Hollingsworth J. 2020. Stable rate of slip along the Karakax section of the Altyn Tagh Fault from observation of interglacial and postglacial offset morphology and surface dating. J Geophys Res-Solid Earth, 125: e2019JB018893

Petersen M D, Dawson T E, Chen R, Cao T, Wills C J, Schwartz D P, Frankel A D. 2011. Fault displacement hazard for strike-slip faults. Bull Seismol Soc Am, 101: 805-825

Ritts B D, Biffi U. 2000. Magnitude of post-Middle Jurassic (Bajocian) displacement on the central Altyn Tagh fault system, northwest China. Geol Soc Am Bull, 112: 61-74

Rockwell T K, Lindvall S, Dawson T, Langridge R, Lettis W, Klinger Y. 2002. Lateral offsets on surveyed cultural features resulting from the 1999 Izmit and Duzce earthquakes, Turkey. Bull Seismol Soc Am, 92: 79-94

Rowan M G, Peel F J, Vendeville B C. 2004. Gravity-driven fold belts on passive margins. In: McClay K R, ed. Thrust Tectonics and Hydrocarbon Systems. Tulsa: AAPG Memoir. 157-182

Scott C, Champenois J, Klinger Y, Nissen E, Maruyama T, Chiba T, Arrowsmith R. 2019. The 2016 M7 Kumamoto, Japan, earthquake slip field derived from a joint inversion of differential lidar topography, optical correlation, and InSAR surface displacements. Geophys Res Lett, 46: 6341-6351

Shao Y X, Liu-Zeng J, Oskin M E, Elliott A J, Wang P, Zhang J Y, Yuan Z D, Li Z G. 2018. Paleoseismic investigation of the Aksay restraining double-bend, Altyn Tagh fault, and its implication for barrier-breaching ruptures. J Geophys Res-Solid Earth, 123: 43074330

Shen Z K, Wang M, Li Y X, Jackson D D, Yin A, Dong D N, Fang P. 2001. Crustal deformation along the Altyn Tagh fault system, western China, from GPS. J Geophys Res, 106: 30607-30621

Sieh K, Jones L, Hauksson E, Hudnut K, Eberhart-Phillips D, Heaton T, Hough S, Hutton K, Kanamori H, Lilje A, Lindvall S, McGill S F, Mori J, Rubin C, Spotila J A, Stock J, Kie Thio H, Treiman J, Wernicke B, Zachariasen J. 1993. Near-field investigations of the Landers earthquake sequence, April to July 1992. Science, 260: 171-176

Spotila J A, Sieh K. 1995. Geologic investigations of a "slip gap" in the surficial ruptures of the 1992 Landers earthquake, southern California. J Geophys Res, 100: 543-559

Tapponnier P, Xu Z Q, Roger F, Meyer B, Arnaud N, Wittlinger G, Yang J S. 2001. Oblique stepwise rise and growth of the Tibet plateau. Science, 294: 1671-1677 
Teran O J, Fletcher J M, Oskin M E, Rockwell T K, Hudnut K W, Spelz R M, Akciz S O, Hernandez-Flores A P, Morelan A E. 2015. Geologic and structural controls on rupture zone fabric: A fieldbased study of the $2010 M_{\mathrm{w}} 7.2 \mathrm{El}$ Mayor-Cucapah earthquake surface rupture. Geosphere, 11: 899-920

Tian Y Y, Xu C, Chen J, Zhou Q, Shen L L. 2017. Geometrical characteristics of earthquake-induced landslides and correlations with control factors: A case study of the 2013 Minxian, Gansu, China, $M_{\mathrm{w}} 5.9$ event. Landslides, 14: 1915-1927

Treiman J A, Lundberg M, compilers. 1999. Fault number 125e, San Jacinto fault, Borrego Mountain section. In: Quaternary Fault and Fold Database of the United States. U.S. Geological Survey website, https:/earthquakes.usgs.gov/hazards/qfaults

Treiman J A, Kendrick K J, Bryant W A, Rockwell T K, McGill S F. 2002. Primary surface rupture associated with the $M_{\mathrm{w}} 7.116$ October 1999 Hector mine earthquake, San Bernardino County, California. Bull Seismol Soc Am, 92: 1171-1191

Valagussa A, Marc O, Frattini P, Crosta G B. 2019. Seismic and geological controls on earthquake-induced landslide size. Earth Planet Sci Lett, 506: 268-281

Washburn Z, Arrowsmith J R, Dupont-Nivet G, Wang X F, Zhang Y Q, Chen Z L. 2003. Paleoseismology of the Xorxol segment of the central Altyn Tagh fault, Xinjiang, China. Ann Geophys, 46: 10151034

Wells D L, Coppersmith K J. 1994. New empirical relationships among magnitude, rupture length, rupture width, rupture area, and surface displacement. Bull Seismol Soc Am, 84: 974-1002

Wesnousky S G. 2006. Predicting the endpoints of earthquake ruptures. Nature, 444: 358-360

Wright T J, Parsons B, England P C, Fielding E J. 2004. InSAR observations of low slip rates on the major faults of western Tibet. Science, 305: 236-239

Xu X W, Tan X B, Yu G H, Wu G D, Fang W, Chen J B, Song H P, Shen J. 2013. Normal- and oblique-slip of the 2008 Yutian earthquake: Evidence for eastward block motion, northern Tibetan Plateau. Tectonophysics, 584: 152-165

Xu X W, Yu G H, Klinger Y, Tapponnier P, Van der Woerd J. 2006.
Reevaluation of surface rupture parameters and faulting segmentation of the 2001 Kunlunshan earthquake $\left(M_{\mathrm{w}} 7.8\right)$, northern Tibetan Plateau, China. J Geophys Res, 111: B05316

Yin A, Rumelhart P E, Butler R, Cowgill E, Harrison T M, Foster D A, Ingersoll R V, Zhang Q, Zhou X Q, Wang X F, Hanson A, Raza A. 2002. Tectonic history of the Altyn Tagh fault system in northern Tibet inferred from Cenozoic sedimentation. Geol Soc Am Bull, 114: $1257-1295$

Youngs R R, Arabasz W J, Anderson R E, Ramelli A R, Ake J P, Slemmons D B, McCalpin J P, Doser D I, Fridrich C J, Swan F H, Rogers A M, Yount J C, Anderson L W, Smith K D, Bruhn R L, Knuepfer P L K, Smith R B, dePolo C M, O'Leary D W, Coppersmith K J, Pezzopane S K, Schwartz D P, Whitney J W, Olig S S, Toro G R. 2003. A methodology for probabilistic fault displacement hazard analysis (PFDHA). Earthq Spectra, 19: 191219

Yuan Z D, Liu-Zeng J, Wang W, Weldon R J, Oskin M E, Shao Y X, Li Z G, Wang P, Zhang J Y. 2018. A 6000-year-long paleoseismologic record of earthquakes along the Xorkoli section of the Altyn Tagh fault, China. Earth Planet Sci Lett, 497: 193-203

Yue Y, Ritts B D, Graham S A. 2001. Initiation and long-term slip history of the Altyn Tagh Fault. Int Geol Rev, 43: 1087-1093

Zachariasen J, Sieh K. 1995. The transfer of slip between two en echelon strike-slip faults: A case study from the 1992 Landers earthquake, southern California. J Geophys Res, 100: 15281-15301

Zhang H, Ge Z X. 2017. Stepover rupture of the $2014 M_{\mathrm{w}} 7.0$ Yutian, Xinjiang, Earthquake. Bull Seismol Soc Am, 107: 581-591

Zhou Q, Xu X W, Yu G H, Chen X C, He H L, Yin G M. 2010. Width distribution of the surface ruptures associated with the Wenchuan Earthquake: Implication for the setback zone of the seismogenic faults in postquake reconstruction. Bull Seismol Soc Am, 100: 2660-2668

Zinke R, Hollingsworth J, Dolan J F. 2014. Surface slip and off-fault deformation patterns in the $2013 M_{\mathrm{W}} 7.7$ Balochistan, Pakistan earthquake: Implications for controls on the distribution of nearsurface coseismic slip. Geochem Geophys Geosyst, 15: 50345050 